\title{
THE DOYNE LECTURE
}

\section{REFLECTIONS ON THE TEARS}

\author{
A. J. BRON \\ Oxford
}

\section{INTRODUCTION}

Robert Doyne, Founder of the Oxford Congress, was born in 1857 and came to Oxford in $1886 .{ }^{1} \mathrm{He}$ lived with his family at 53 Broad Street, not far from Keble College, which was later to become his college when he was appointed Margaret Ogilvie's Reader. Mrs Ogilvie, who created the readership, was married to one of the consulting ophthalmologists of that time. Doyne started the Oxford Eye Dispensary in a builder's yard, but shortly after, he established the Eye Hospital at 21-22 Wellington Square, now the site of the University Chest. It found its present site in Walton Street almost exactly 100 years ago, in the fever block of the Radcliffe Infirmary. Although after retirement Doyne moved to London, he died in Oxford following a stroke in 1916, in a house on the Woodstock Road, opposite to the church of St Phillip and St James. Doyne wrote over 87 papers and made a similar number of presentations in his clinical lifetime. At least one of these had implications for the topic of dry eye ${ }^{2}$ the subject of this lecture.

This paper is about the classification, diagnosis and management of dry eye and its message is that in recent years we have come to a far better understanding of the disease and now have more rational opportunities for therapy. To set the scene I will briefly describe some normal features of the tear system.

\section{TEAR STRUCTURE AND FUNCTION}

Wolff's ${ }^{3}$ (1946) view of tear film structure is still current and was summarised in an earlier paper. ${ }^{4}$ The tear film has lipid, aqueous and mucin layers, the lipid deriving from the meibomian oil glands, the

Correspondence to: Professor A. J. Bron, Nuffield Laboratory of Ophthalmology, University of Oxford, Walton Street, Oxford OX2 6AW, UK. Tel: +44 (01865) 248996. Fax: +44 (01865) 794508. aqueous from the lacrimal glands and the mucin from the goblet cells and epithelia of the ocular surface.

\section{Meibomian Lipid}

The meibomian oil is a product of the meibomian glands of the lids. The glands and their vessels are richly innervated by cholinergic, VIPergic, and NPYergic fibres. ${ }^{5}$ The VIPergic fibres are thought to be conveyed by the facial nerve via the pterygopalatine pathway. ${ }^{6}$ NPYergic fibres commonly run with the sympathetic nervous system, but since acinar innervation by tyrosine hydroxylase (TH)-positive nerves is sparse, it is assumed that these NPY fibres have some other origin. ( $\mathrm{TH}$ is concerned with catecholamine synthesis and postganglionic sympathetic fibres are generally $\mathrm{TH}$ positive.) There is also a sensory acinar innervation by SP- and CGRPergic fibres and a rich vascular innervation by cholinergic and VIPergic fibres, all of which may influence inflammatory responses in the lids. Recently androgen receptors have been identified in the meibomian gland as well as in the lacrimal gland. ${ }^{7}$

\section{Secretion and Delivery of Meibomian Oil}

Blink action was first suggested to be of importance to oil delivery by Linton et al. ${ }^{8}$ in 1961 . A few years later McDonald 9 observed 'jetting' of oil onto the human tear film immediately following the blink, again suggesting a role for lid action. Recently we have confirmed by the technique of meibometry, that the process of oil delivery is dependent on secretion, aided by blink action. ${ }^{10}$

Meibometry is a technique developed in Oxford in collaboration with Professor S. Dikstein of the Hadasseh University. It involves taking a lipid sample from the lower lid margin, with a loop of tape, and reading the change in transparency, densitometrically. ${ }^{11-13}$ Such studies show a rise in the resting level, or 'casual level', of lipid on the lid margin with age in both sexes. Lower levels in 
women, between puberty and the menopause, suggests a hormonal influence. The reason for this increase in casual levels with age is not understood and it could reflect a decrease in oil excretion with age rather than an increase in secretion. ${ }^{14}$

Using a combination of meibometry and interference microscopy it is possible to calculate that the lid margin reservoir of oil is about $300 \mu \mathrm{g}$ in the adult, while the preocular film holds about $9 \mu \mathrm{g}$ of lipid, suggesting that there are normally ample marginal reserves of lipid for supply to the preocular tear film with each blink. ${ }^{15}$

Meibometry has also been used to explore the secretion and delivery of the lid oil. If the lid margins are completely cleaned of lipid, with a solvent such as hexane, then, over a period of 3 minutes and in the absence of blinking, little or no lid oil is restored to the lid margin, thus supporting the role of the blink in oil delivery in the short term. However, when blinking is absent in the longer term, for up to 45 minutes, as during general anaesthesia, then a different picture emerges. ${ }^{16}$ There is a rise in the level of oil on the lid margin over time, indicating that the secretory process is capable of maintaining oil delivery in the absence of lid action. We have therefore concluded that there is a steady secretion of meibomian oil onto the lid margins over 24 hours, but that in the waking state, delivery is aided by blink action. We assume that the rate of secretion is regulated by neural, hormonal and other factors.

Chew has shown that the casual oil level is highest just after waking and that it is lower in the late morning and at the end of the day. ${ }^{10,11}$ Our explanation for this diurnal variation is that, during overnight sleep and in the absence of blinking, the secretory pressure in the ducts rises to a critical level which ensures continued oil delivery. On waking, the excess oil is discharged onto the lid margins as blinking resumes (Figs. 1, 2).

If, as seems likely, the ductular system takes a variable amount of time to fill from gland to gland, then the critical pressure will not be achieved in every gland at any one time and delivery will be both intermittent and non-simultaneous. This fits in with the report of Norn ${ }^{14}$ that only $45 \%$ of glands are expressible at a given time.

If our assumptions are true, then the ducts are relatively distended overnight and the excess is discharged on waking. This has direct relevance to the advice which we give to patients with oil gland obstruction. There is clearly good reason to institute a programme of heat and lid massage shortly after waking.
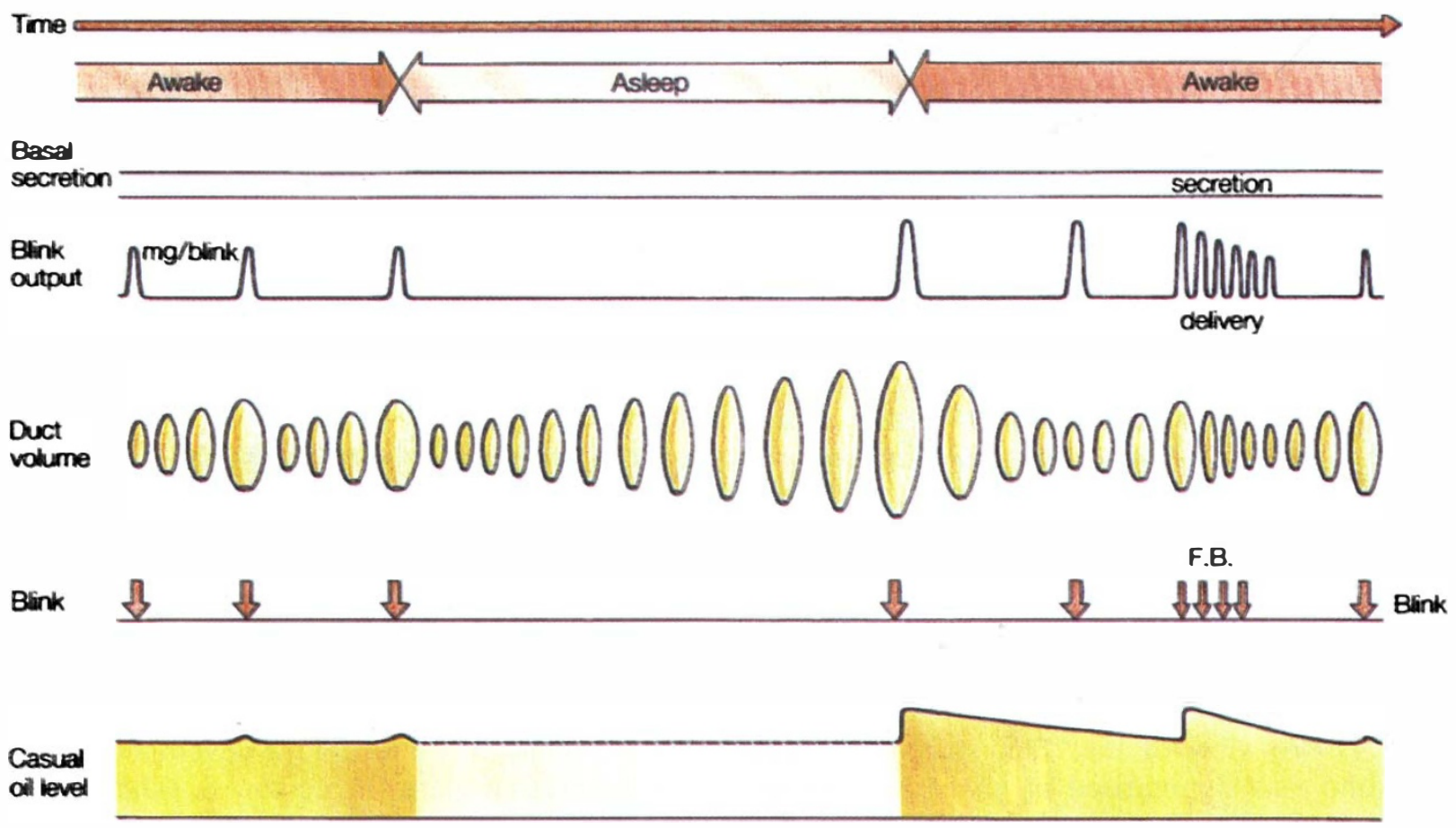

Fig. 1. Oil secretion and delivery (schematic). The events shown are, from above downwards: 1, Time. 2, Waking and sleeping states. 3, A 'basal' level of secretion. 4, Blink output; the delivery of meibomian oil with each blink. Note that on waking after sleep, an increased output with early blinks is conceived because of overnight accumulation. A series of fast blinks (to the right) results in a decreased output per blink since the reservoir is depleted. 5, Duct volume: it is assumed that there is a minute increase in volume between blinks and a further increase in volume during sleep, when the lids are closed. The excess volume is depleted on waking, with the resumption of blinks. 6, Blink timing: F.B. = a series of fast blinks. 7, Casual level of meibomian oil on the lid margin. Note that the level is increased after waking, as the overnight accumulation of oil is discharged to the lid. 


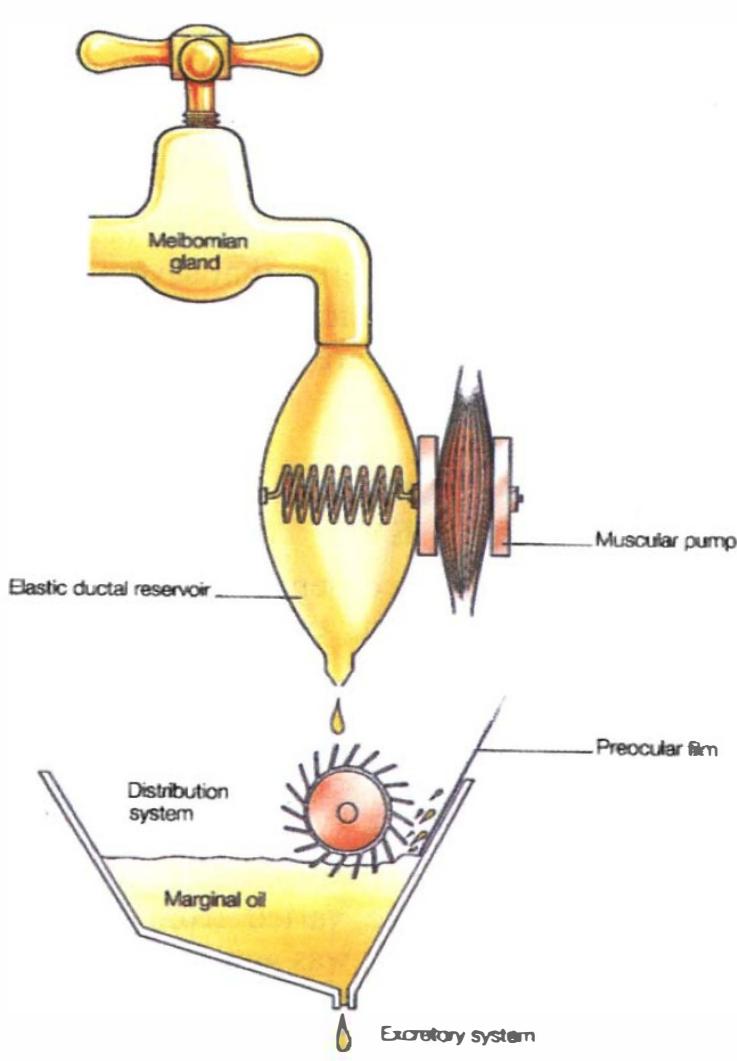

Fig. 2. Schematic representation of the mechanisms of meibomian oil secretion and delivery. Meibomian oil is secreted into an elastic ductal reservoir. Oil delivery on to the lid margin is influenced by the secretory rate. It is assumed that oil delivery occurs when the ductal pressure exceeds a critical level. This level could vary from gland to gland. The muscular action of the blink raises intraductal pressure above the critical level in a proportion of glands and results in delivery from these glands. The opening phase of the blink is also involved in the distribution of oil from the marginal reservoir on to the preocular tear film. It is assumed that the excretion of oil from the marginal reservoir occurs partly by diffusion on to the skin of the lid and to a lesser extent following diffusion across the tear layer, via the mucous thread, after contamination of the ocular mucus.

Little is written about the excretion of meibomian oil and it is a subject which does not appear to have received study. At present, we assume that oil is lost directly onto the skin of the lid margin, since the preocular lipid film stretches between the skin of the upper and lower lid, anterior to the mucocutaneous junctions, and is segregated from the canalicular apparatus whose puncta open onto the mucous membrane of the lid. Loss of meibomian lipid by diffusion through the aqueous laye ${ }^{17}$ is likely to be small, and only lipid which has contaminated and complexed with the tear mucous layer will be able to exit via the puncta, presumably in the mucous thread. $^{18}$

\section{Aqueous Tears}

The aqueous portion of the tears is secreted by the lacrimal glands. The main, palpebral and accessory parts of the lacrimal gland are innervated ${ }^{19,20}$ and each portion would therefore be expected to participate in the reflex responses of the gland. There is no reason to suppose that the role of the accessory glands is simply to provide a basal flow. ${ }^{21}$ Indeed in 1980 Jordan and Baum ${ }^{22}$ proposed that there is no such thing as basal flow and that reflex tear secretion is stimulated when the eyes first open in the morning and are exposed to environmental stimuli. Since reflex tear flow, as measured by the Schirmer test, is not abolished by topical anaesthesia, it suggests that some of these environmental stimuli are non-ocular. Thus the Schirmer response can be further reduced by nasal anaesthesia. ${ }^{23}$

It is of clinical importance that those parts the lacrimal glands which directly abut the conjunctival sac (the palpebral and accessory parts) are accessible to topical therapy intended to affect lacrimal secretion and the ocular surface directly. Topically applied drugs may pass through the conjunctival mucosa to act on the deeper tissues of the lid. Thus topical adrenaline can access the fibres of Müller's muscle inserting into the upper tarsal plate and will elevate the ptotic lid in postganglionic Horner syndrome; conversely, topical guanethidine will induce ptosis in the normal subject. It follows that the palpebral part of the lacrimal gland, presenting in the lateral fornix and the accessory glands of the superior fornix, should be accessible to drugs delivered into the conjunctival sac. This is relevant to the topical use of drugs instilled to stimulate lacrimal secretion or reduce lacrimal and ocular surface inflammation. It should be noted that the lacrimal mass is lower in women than in men.

\section{Mucin}

Mucin has been said to form the deepest layer of the preocular tear film ${ }^{3,24}$ and was originally thought to derive entirely from the conjunctival goblet cells, whose distribution was described by Kessing. ${ }^{25}$ Early studies inferred, on the basis of histochemistry and studies on goblet cells elsewhere in the body, that the conjunctival goblet cells secreted a high-molecularweight, polymeric mucin glycoprotein with lubricant and surface tension lowering properties. ${ }^{26,27}$ Later, on the basis of electron histochemical studies, an additional source of mucin was proposed, arising from sub-surface vesicles in the conjunctiva. ${ }^{28}$ Like the studies which had preceded them, these studies were suggestive, but the techniques employed were non-specific.

Recently several genes for human mucin have been cloned (MUC 1-8) and there is evidence from $\mathrm{Dr}$ Gipson's laboratory in Boston, using 
immunohistochemical techniques and in situ hybridisation, that the surface epithelial cells of the cornea and conjunctiva express MUC 1 (a transmembrane mucin), the stratified epithelium of the conjunctiva MUC 4, and the goblet cells MUC 5, these latter mucins being secretory in type. ${ }^{29-31}$ MUC 1 is the most likely candidate for the glycocalyx at the apical surface of the superficial ocular surface cells.

The story for the tears themselves appears less clear. Several groups have reported mucin glycoproteins in the tears at masses exceeding $700 \mathrm{kDa}^{32-34}$ Bolis et al..$^{32}$ but not Sack et al. ${ }^{33}$ identified MUC 1 in the tears, while Ellingham et al. ${ }^{34}$ demonstrated two fractions similar to those found in conjunctival homogenates. Our own studies, however, have failed to demonstrate the presence of soluble mucins of sufficient molecular weight (i.e. over $1000 \mathrm{kDa}$ ) to fully explain the viscous properties of the tears. ${ }^{35}$

\section{The Role of Tear Mucin}

For some time it has been the view that mucin performs at least two important functions: those of wetting and lubrication.

Holly and Lemp ${ }^{26,36}$ proposed that the surface cells of the normal cornea and conjunctiva were basically hydrophobic and that mucin, by lowering the surface tension of the tears, permitted the surface to be wetted. Mucins and their effects on surface tension were thus thought to have an important role in tear stability. This view arose from studies which showed that 'removal of mucin' from the cornea by physical or chemical wiping, rendered the epithelium hydrophobic and non-wettable. Its hydrophilic, wettable state was restored on reapplying mucin and it was concluded from this that mucins conferred wettability to the ocular surface.

However, Cope et al. ${ }^{37}$ and Liotet et al..$^{38}$ subsequently showed that the methods used to remove mucin in these experiments were themselves damaging to the ocular surface and concluded that the hydrophobic state observed had been induced artefactually. If mucin was removed gently with acetyl cysteine, the native surface remained wettable. It was inferred that the normal surface of the eye is wettable, probably because of the presence of an intact glycocalyx. It may well be that mucin plays an important role in restoring the wettability of a damaged ocular surface, but it seems that the native surface is already wettable and that tear mucin may be performing some other functions.

Human tears have a low surface tension (about $40-46 \mathrm{mN} / \mathrm{m}$ ) compared with water (about $72 \mathrm{mN} / \mathrm{m}$ ) and a high viscosity (a relative viscosity of $4-5$ at a shear rate of $\left.5 \mathrm{~s}^{-1}\right) .{ }^{27}$ Their rheological properties are non-Newtonian, i.e. they 'shear thin' so that their viscosity falls in conditions of high shear. This is thought to achieve a stable tear film when the eye is stationary and fixating on a target, and to provide lubrication between the lids and globe during the blink or saccade. Since there is currently no evidence for the presence of polymeric mucin in the tears (i.e. with a molecular weight of $1000 \mathrm{kDa}$ or more), the basis of the rheological and surface tension properties of the tears is less certain than in the past. ${ }^{39}$ It is therefore of interest that several groups, including our own, have identified surface-active agents in the tears that are capable of lowering surface tension. ${ }^{40-42}$

\section{CLASSIFICATION AND DIAGNOSIS OF DRY EYE}

In recent years, a partial consensus has been reached in Europe and other parts of the world over the classification of dry eye (see below). The debate has been helped by the report of the recent NEI/Industry workshop on dry eye (1996), which concerned itself with classification and the selection of tests for clinical trials. ${ }^{43}$

At this workshop it was recognised that the terms used to describe dry eye varied from country to country and on this basis it was agreed to regard the terms 'dry eye' and 'keratoconjunctivitis sicca' (KCS) as synonymous.

The two major categories of dry eye were described as tear-deficient dry eye (TDDE), in which there is a deficiency of the lacrimal component of the tears, and evaporative dry eye (EDE), where the cause is excessive evaporation. These major groups are not mutually exclusive and their further subdivisions are given in Fig. 3.

This classification can be looked at fruitfully in another way by examining the manner in which tests are applied to fully characterise a dry eye patient. Fig. 4 is a 'diagnostic pinwheel' which shows how the diagnostic process is built up. The components of aqueous-deficient dry eye are located in the upper half of the pinwheel and of evaporative dry eye in the lower half. It will be observed that mucin deficiency is not represented as a separate category of dry eye, because mucin deficiency is a feature of both teardeficient and evaporative states and therefore has no discriminatory value.

\section{Global Features of Dry Eye}

An important consequence of this approach is that it identifies a set of global features (symptoms, ocular surface damage, reduced tear stability and tear hyperosmolality) which characterise any form of dry eye, are the core of the diagnostic process, but do not establish aetiology.

For the patient, symptoms are the essence of the disorder, whereas pathologically dry eye is defined by the presence of ocular surface damage. Tear instability appears to be a component of all forms of dry eye 


\section{Classification of Dry Eye}

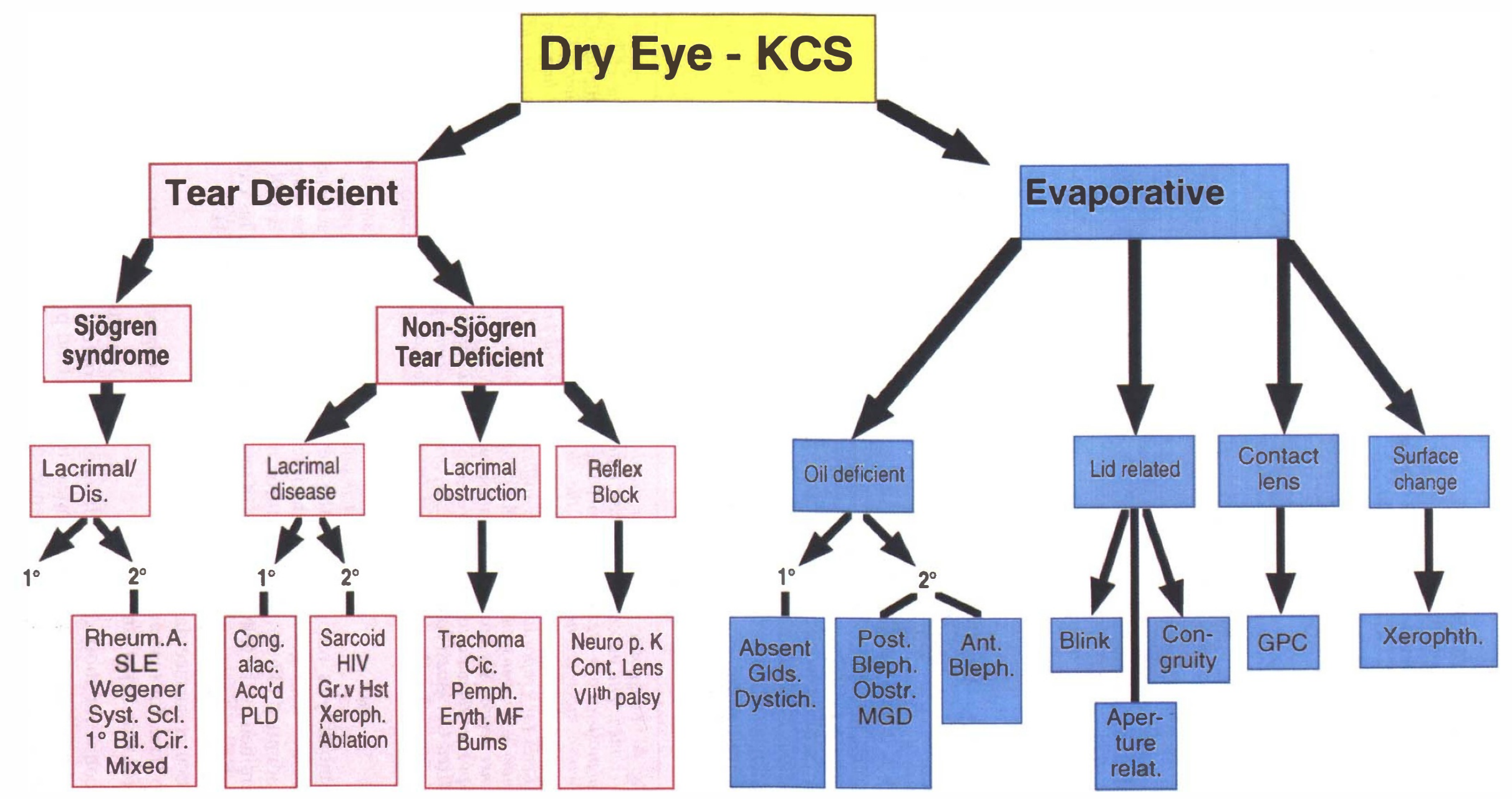

Fig. 3. Classification of dry eye. Rheum. A., rheumatoid arthritis; SLE, systemic lupus erythematosus; Wegener, Wegener's granulomatosis; Syst. Scl., systemic sclerosis; $1^{\circ}$ bil. cir., primary biliary cirrhosis; Cong. alac., congenital alacrima; Acq'd PLD, acquired primary lacrimal gland disease; Gr. v Hst, graft-versus-host disease; Xeroph., xerophthalmia; Cic. Pemph., cicatricial pemphigoid; Eryth. MF, erythema multiforme; Neuro. p.k., neuroparalytic keratitis; Cont. Lens, contact lens; Absent Glds., absent glands; Distich., distichiasis; Post. Bleph., posterior blepharitis; Obstr. MGD, obstructive meibomian gland disease; Ant. Bleph., anterior blepharitis; Congruity, lid/surface incongruity; Blink, blink abnormalities; GPC, giant papillary conjunctivitis. 


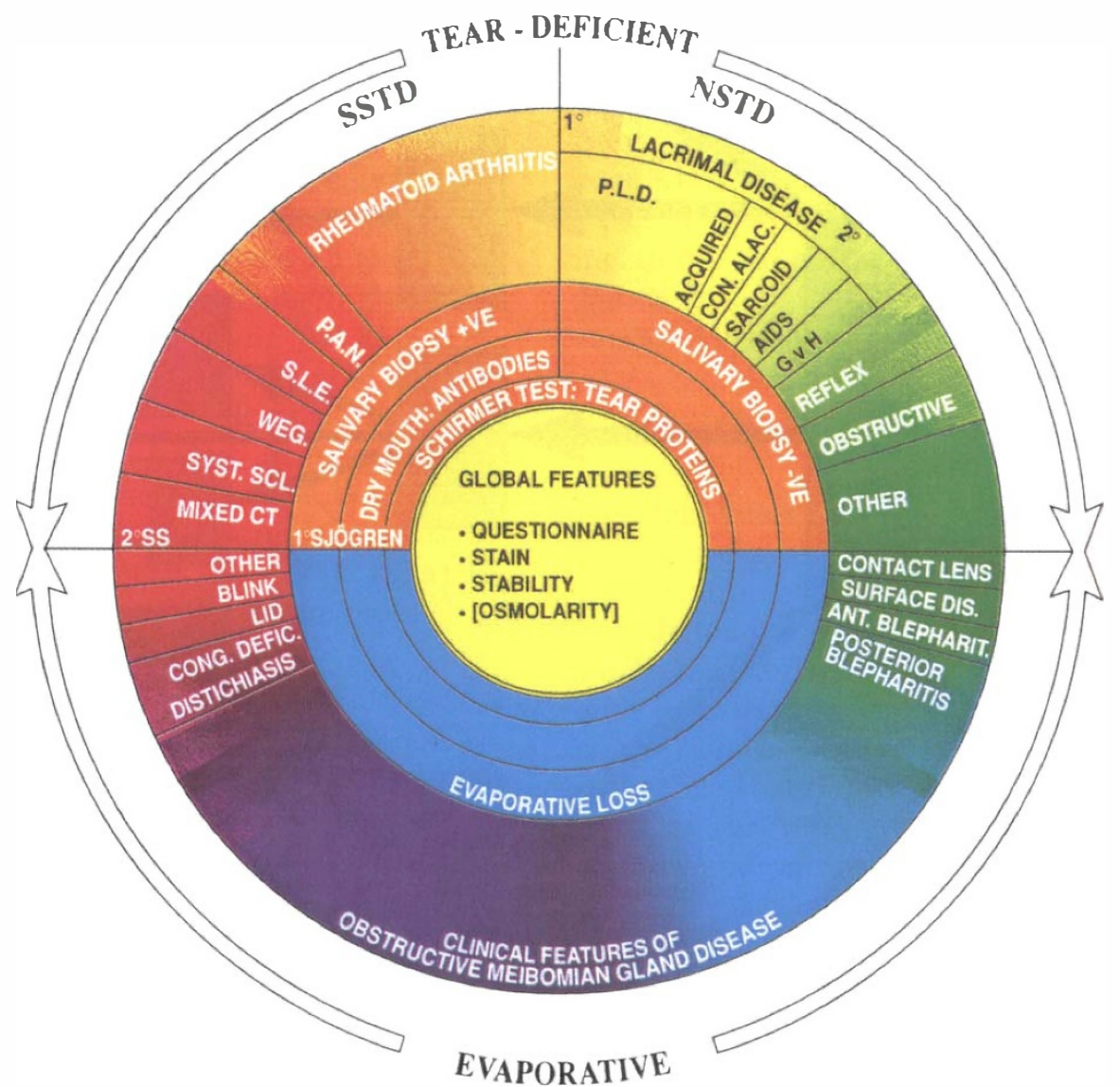

Fig. 4. Diagnostic pinwheel for the dry eye. Criteria for the diagnosis of dry eye are presented. The hub of the pinwheel represents the criteria applied to establish the global diagnosis of dry eye. These characterise the disorder of the eye without specifying cause. Two or more are necessary for the identification of the dry eye state. The criteria for aqueous-deficient dry eye are above the horizontal line; below the horizontal line are criteria for evaporative (aqueous-sufficient) dry eye. Tests for Sjögren syndrome are at upper left, inner sector; tests for non-Sjögren aqueous-deficient dry eye are at upper right, inner sector. See text for full discussion. P.A.N., polyarteritis nodosa; S.L.E., systemic lupus erythematosus; WEG, Wegener's granulomatosis; Syst.Scl., systemic sclerosis; Mixed CT, mixed-combined; P.L.D., primary lacrimal gland disease; ALAC., congenital alacrima; $G \vee H$, graft versus host disease; Surface dis., surface disease.

and tear hyperosmolarity is recognised as the key mechanism for surface damage, ${ }^{44-46}$ although other mechanisms are admitted. These global features of dry eye can be identified by the following types of test:

(i) A questionnaire for symptoms

(ii) Staining, for ocular surface damage

(iii) The break-up time, for tear instability

(iv) Osmometry, for tear hyperosmolarity

Such features account for most dry eyes, although most clinicians will recognise patients who appear to have signs of surface damage in the absence of symptoms, or symptoms associated with minimal surface damage.
Further characterisation of dry eye into aqueous tear-deficient or evaporative, requires additional diagnostic tests which will discriminate one aetiology from another. This can be followed on the diagnostic pinwheel (Fig. 4).

\section{Tear-Deficient Dry Eye}

Demonstration of reduced aqueous flow, or reduced content of tear lysozyme or lactoferrin (two lacrimal gland proteins), places the patient in the category of a tear-deficient dry eye; serological abnormalities or signs of systemic autoimmune disease would suggest a diagnosis of Sjögren syndrome dry eye (SSDE). 


\section{Dry Eye as a Part of Sjögren Syndrome}

Sjögren syndrome is an autoimmune exocrinopathy which may manifest as a primary disorder (primary Sjögren syndrome), with dry eye, dry mouth, a positive focus score on minor salivary gland biopsy and the presence of antibodies indicative of autoimmune disease (e.g. anti-tissue antibodies and antiRo and anti-La). Alternatively, it may accompany certain autoimmune connective tissue disorders such as systemic lupus erythematosus, polyarteritis nodosa, Wegener's syndrome, primary biliary cirrhosis and mixed connective tissue disorder, as secondary Sjögren syndrome.

Criteria for the connective tissue component of these disorders have been laid down in earlier reports such as those of the American Rheumatism Association $^{47-49}$ and attempts have been made recently to establish diagnostic criteria for Sjögren syndrome itself in studies carried out in Europe and Japan. ${ }^{50-53}$

In the multicentre European Community study reported by Vitali et al. ${ }^{52}$ a positive finding for four of six listed criteria (Tables I, II) was highly diagnostic for primary Sjögren syndrome, with a sensitivity of $93.5 \%$ and a specificity of $94.5 \%$. A positive response to any category listed under items 1 and 2 , in combination with a positive response to at least two items listed in categories 3, 4 and 5, was diagnostic for secondary Sjögren syndrome, with a sensitivity of $93.5 \%$ and a specificity of $94 \%$. It will be noted that since two of the questions used to characterise dry eye with these criteria are not independent of the prior diagnosis of dry eye, the criteria might be of less value for a screening programme than in a prevalence study.

\section{Non-Sjögren Dry Eye}

In the presence of the global features of dry eye and with evidence for lacrimal dysfunction, but not of autoimmune disease, the diagnosis would be nonSjögren dry eye (NSDE), which would be further characterised by relatively soft diagnostic features. The commonest form is a primary, age-related condition, in which no other aetiology can be identified. The term adopted in the NEI/Industry workshop was acquired primary lacrimal deficiency (PLD) ${ }^{43}$ congenital alacrima would be designated congenital PLD. Acquired PLD is a diagnosis of exclusion, and is what most clinicians mean when they use the term dry eye or KCS casually, in an older, healthy patient. But in a young patient with graft-versus-host disease (in whom primary NSDE would be uncommon), the presence of NSDE would suggest that the dry eye was due to the rejection. ${ }^{54,55}$ In an older patient there would be some diagnostic confusion. AIDS-related dry eye falls into the NSDE category and can be distinguished from the dry eye

Table I. European criteria for the diagnosis of Sjögren syndrome

\section{Ocular symptoms}

Definition. A positive response to at least one of the following three questions:

(a) Have you had daily, persistent, troublesome dry eyes for more than 3 months?

(b) Do you have a recurrent sensation of sand or gravel in the eyes?

(c) Do you use tear substitutes more than 3 times a day?

\section{Oral symptoms}

Definition. A positive response to at least one of the following three questions:

(a) Have you had a daily feeling of dry mouth for more than 3 months?

(b) Have you had recurrent or persistently swollen salivary glands as an adult?

(c) Do you frequently drink liquids to aid in swallowing dry foods?

\section{Ocular signs}

Definition. Objective evidence of ocular involvement, determined on the basis of a positive result on at least one of the following two tests:

(a) Schirmer I test $(\leqslant 5 \mathrm{~mm}$ in 5 minutes)

(b) Rose Bengal score ( $\geqslant 4$, according to the van Bijsterveld scoring system)

\section{Histopathological features}

Definition. Focus score $\geqslant 1$ on minor salivary gland biopsy (focus defined as an agglomeration of at least 50 mononuclear cells; focus score defined as the number of foci in $4 \mathrm{~mm}^{2}$ of glandular tissue)

5. Salivary gland involvement

Definition. Objective evidence of salivary gland involvement, determined on the basis of a positive result on at least one of the following three tests:
(a) Salivary scintigraphy
(b) Parotid sialography
(c) Unstimulated salivary flow $(\leqslant 1.5 \mathrm{ml}$ in 15 minutes)

6. Autoantibodies

Definition. Presence of at least one of the following serum autoantibodies:
(a) Antibodies to Ro/SS-A or La/SS-B antigens
(b) Antinuclear antibodies
(c) Rheumatoid factor

Exclusion criteria: pre-existing lymphoma, acquired immunodeficiency syndrome, sarcoidosis, or graft-versus-host disease

From Vitali et al. ${ }^{52}$ with permission. 
Table II. Japanese criteria for the diagnosis of dry eye

Diagnosis is based on the following:

1. Abnormality of tear quality or quantity

2. Evidence of damage to corneal or conjunctival epithelium (due to items listed in 1)

A definitive diagnosis is made when 1 and 2 are positive. A suspect dry eye is diagnosed when 1 or 2 is positive.

The tests employed are:

For item 1:

(i) Schirmer test $\leqslant 5 \mathrm{~mm}$

(ii) Cotton thread $\leqslant 10 \mathrm{~mm}$

(iii) Fluorescein break-up time $\leqslant 5$ seconds

If (i), (ii) or (iii) are satisfied, this is a positive.

For item 2:

(i) Fluorescein staining score $\geqslant 1$ for the cornea ${ }^{a}$

(ii) Rose Bengal score $\geqslant 3$ for the conjunctiva ${ }^{b}$

If (i) or (ii) are satisfied, this is a positive.

Modified from Shimazaki. ${ }^{53}$

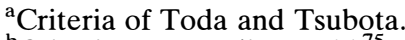

${ }^{\mathrm{b}}$ Criteria of van Bjisterveld. ${ }^{75}$

of Sjögren syndrome by the presence of a high T8/T4 ratio in the lacrimal gland in AIDS-related dry eye, the reverse of the situation in SSDE. ${ }^{56}$

Some lesser-known causes of dry eye under the category of NSDE include that related to a reduced reflex stimulation of the tears, occurring in diabetics ${ }^{57}$ and in contact lens wearers whose corneal sensitivity has been reduced by contact lens wear. ${ }^{58}$

\section{Evaporative Dry Eye}

If we now consider evaporative dry eye, by far and away the most common cause is obstructive meibomian gland disease (MGD), a condition characterised by meibomian gland drop-out, reduced expressibility of oil secretions, altered oil quality and morphological changes involving the meibomian orifices, ducts and glands. ${ }^{59,60}$ Other causes include disturbances of the width of the palpebral aperture, of lid/globe congruity and of the blink response; for instance reduced blinking in Parkinson's disease may induce a diffuse dellen, and a compensatory reduced blink rate is also recorded as a cause of dry eye in dermatochalasis. $^{61}$

The key test for evaporative dry eye is the measurement of water loss by evaporimetry as carried out by Rolando and Refojo ${ }^{62}$ and Mathers. ${ }^{63}$ Mathers et al. ${ }^{60}$ have shown that in patients with chronic blepharitis, obstructive MGD is associated with increased tear evaporation. This is the likely basis for the ocular surface changes of the meibomian keratoconjunctivitis which accompanies severe meibomian gland disease. ${ }^{64}$

\section{Diagnostic Tests for Dry Eye}

As noted earlier, classification and diagnosis are inextricably entwined; a selection of diagnostic tests is discussed below to emphasise how both the global and specific features are identified.

\section{Assessment of Symptoms}

Only the questionnaires of McMonnies and $\mathrm{Ho}^{65,66}$ and Schein et al. ${ }^{67}$ have been fully validated. The first of these was generated in a selected clinic population and therefore its applicability to the general population is unknown. The Schein questionnaire was developed for a large population study in Maryland, USA (2240 individuals) (Table III). The study yielded a frequency of dry eye in the population aged $65-85$ years of $14.6 \%$, on the basis of frequent symptoms alone. Based on the Schirmer I test alone (with anaesthesia), the figure was $11.9 \%$, with a similar figure based on Bengal Rose testing alone. This figure fell to between $2.0 \%$ and $2.2 \%$ when those with symptoms and/or a positive Schirmer test were considered, and to $0.7 \%$ in those with the three tests positive. In this large population study, the Schirmer and Bengal Rose tests were poor identifiers of symptoms and, even more surprisingly, there was no correlation of dry eye with age and sex. The high female:male ratio for dry eye usually cited for clinic populations was not found.

\section{Assessment of Surface Damage}

Selection of Dyes. The standard method to demonstrate ocular surface damage, is to stain the ocular surface with fluorescein to show corneal damage and with Bengal Rose to show damage on the bulbar conjunctiva. Certain problems exist with the use of these dyes. Bengal Rose is poorly seen on the cornea against the background of a dark iris and the visibility of fluorescein on the conjunctiva is poor because of the lack of contrast achieved over the highly reflective surface of the sclera.

The value of fluorescein staining can be greatly enhanced if it used in conjunction with a yellow barrier filter, such as a Kodak Wratten 12, in combination with the standard blue exciter filter of the slit lamp. This technique reveals surface damage on the globe as well as cornea. In the clinic it is sufficient to place a single drop of Minims saline (Chauvin Pharmaceutical) on a Fluoret strip (Chauvin Pharmaceutical), shake off the excess and tap lightly onto each lower tarsal plate. The solution applied in this way. is highly fluorescent and readily visible. The use of higher concentrations is not

Table III. Population-based perspective of dry eye: dry eye questionnaire

\footnotetext{
1. Do your eyes ever feel dry?

2. Do you ever feel a gritty or sandy sensation in your eye?

3. Do your eyes ever have a burning sensation?

4. Are your eyes ever red?

5. Do you notice much crusting on your lashes?

6. Do your eyes ever get stuck shut in the morning?
}

Allowable responses: rarely, sometimes, frequently, always From Schein et al. ${ }^{67}$ with permission. 
recommended since there may be insufficient tears to achieve the required dilution and fluorescence.

Fluorescein instillation is very well tolerated, which is a major advantage over Bengal Rose. Bengal Rose, for reasons which include the photoinduction of free radicals and direct cytotoxicity, ${ }^{68}$ causes pain on instillation and, particularly in dry eye patients where the dye is taken up into the surface cells, persistent pain. Pain may outlast by hours or days the duration of the topical anaesthesia commonly employed to perform the test.

Other well-tolerated dyes are available to stain the ocular surface, including Lissamine Green, which is viewed in white light, ${ }^{69}$ and sulphorhodamine $\mathrm{B}$, a fluorescent dye which has a peak absorption and emission of $556 \mathrm{~nm}$ and $572 \mathrm{~nm}$ and is viewed using a band-pass interference filter of $520-550 \mathrm{~nm}$ as exciter and a Kodak Wratten 12 gelatin absorption filter as barrier. The latter transmits $100 \%$ of the light at 600 $\mathrm{nm} .^{70}$ The staining properties of Lissamine Green are similar to those of Bengal Rose in that staining is best seen over the white of the sclera and least over a dark brown iris, where contrast is lost. Sulphorhodamine B behaves more like fluorescein.

Since the work of Norn, ${ }^{71,72}$ Bengal Rose has been regarded as a supravital stain which is taken up by dead and degenerate cells. This has been questioned by Feenstra and Tseng. ${ }^{68,73}$ In the United States Bengal Rose is available on an impregnated paper strip (Rosette-SNP) from which it is released by a drop of saline. In this form it is well tolerated. In the $\mathrm{UK}$ it is marketed as a Minims $1.0 \%$ solution at a $\mathrm{pH}$ 6.8-8.5. The amount of staining achieved with the drop is dose-dependent. ${ }^{18}$ Tseng has proposed that staining of the ocular surface by Bengal Rose is due to loss of the normal mucin coat, so that the dye obtains access to epithelial cells which would normally be protected. Thus he believes that the dye is directly cytotoxic and will stain normal cells if the mucin layer is defective, as it is in the dry eye. ${ }^{68,73}$ This view does not explain the incomplete, punctate nature of the staining pattern, appearing to be confined to individual cells, or the failure to cause diffuse staining in the rabbit model after removal of the mucin layer with acetyl cysteine. From the study of Watanabe and Tanaka ${ }^{74}$ on the effects of corneal injury on Bengal Rose staining, it would appear that staining is associated not with loss of secreted mucin but with loss of a mucin-like material, which could be glycocalyx, at the apical surface of the epithelial cells. This implies, at least, that although staining cells need not necessarily be degenerate to take up stain, they may have suffered impaired expression of a membrane mucin.

Although it is quite possible that these different dyes do not stain identical features of surface damage, it does seem likely that the damage which they quantify is closely interrelated and is diagnostically interchangeable.

Grading Surface Damage. There are several schemes for grading ocular surface staining. The van Bijsterveld schema published in 1969 is well validated and grades each exposed corneal and conjunctival segment from 0 to 3 , to give a maximum score of $9 .{ }^{75}$ No standards are available for comparison, which reduces the value of the scoring system for clinical trial purposes. The system reported by Solomons et al. ${ }^{76}$ records numbers of staining points on the ocular surface.

In Oxford we use a grading chart made up of five panels (Fig. 5), each of which represents typical gradations of stain on either the cornea or conjunctiva. The number of dots per panel increases sequentially on a log-linear scale, to give a grading from 0 to 5 for each segment and a maximum score for the interpalpebral surface of $15 .^{77}$ It is useful to score the upper and lower conjunctiva in addition, since the superior conjunctiva may be involved in severe dry eye, and superior limbic kerato-conjunctivitis (SLK) may accompany dry eye or may be confused with it symptomatically. Staining of the bulbar conjunctiva outside the exposed interpalpebral zone in dry eye could simply reflect a high degree of tear hyperosmolality, but an alternative explanation particularly relevant to the dry eye of Sjögren syndrome, is that it is due to conjunctival inflammatory changes intrinsic to the autoimmune process. ${ }^{78}$ Staining of the lower bulbar conjunctiva has also been remarked as a feature of blepharitis.

\section{Assessment of Tear Stability}

Premature break-up of the tear film is a feature of any form of dry eye and can be recorded by invasive and non-invasive techniques.

The Fluorescein Break-Up Test (FBUT) is the standard test available in the clinic by which to estimate tear stability. ${ }^{79,80}$ It may be regarded as a provocative test, since fluorescein shortens the noninvasive break-up time. ${ }^{81}$ It is best observed using a blue exciter and yellow barrier filter in order to isolate fluorescence in blue-eyed patients where there is a high iris reflectance and low contrast. A referent value of less than 10 seconds is used in diagnosis.

The Non-Invasive Tear Break-Up Test (NIBUT) was developed from an in vitro test for estimating the efficacy of tear substitutes. ${ }^{82}$ The time between the last blink and the break-up of the reflected image of a target from the tear film is the recorded measure. Some commercial instruments are available..$^{83,84}$ Both the NIBUT and FBUT would benefit from a less subjective detection system, since onset may be subtle and the opportunity for bias is great. Golding et al..$^{85}$ have gone some way towards this by 

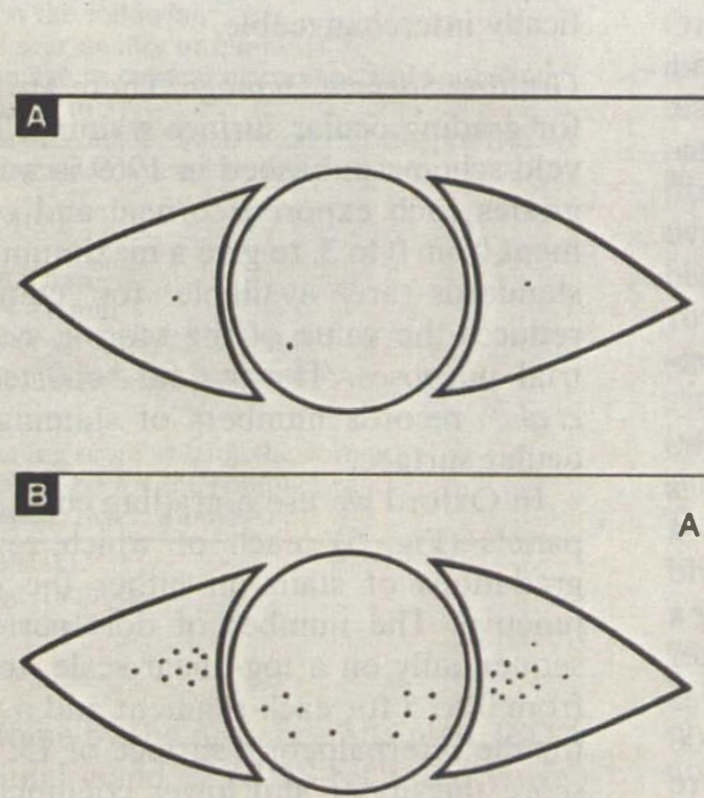

C

Grade

Dot

Count Log

$\begin{array}{lll}0 \leq A & 1 & 0\end{array}$

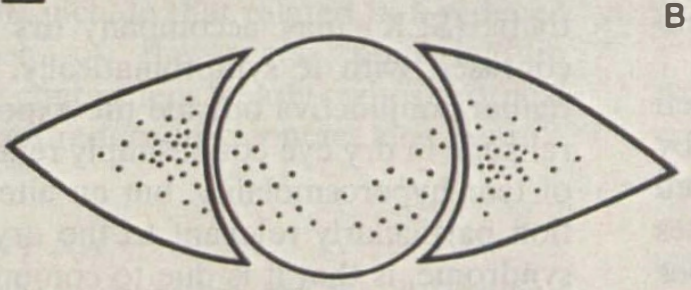

D
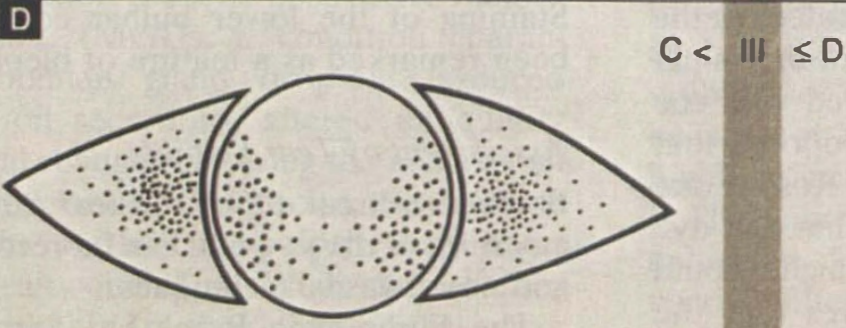

E

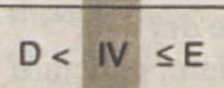

316

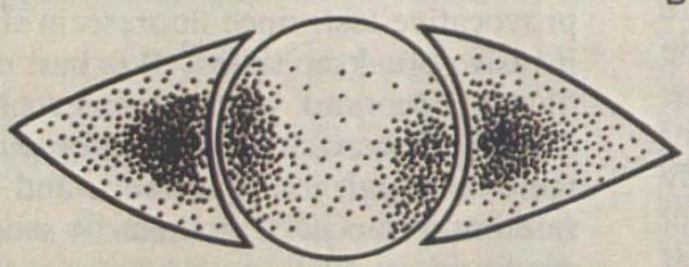

$E<V$

Fig. 5. Grading of corneal and conjunctival staining (Oxford scheme). 
converting the TMS topography system to an on-line video system, so that break-up can be measured in a masked fashion.

\section{Assessment of Tear Osmolality}

There is considerable clinical and experimental work, originating particularly from the laboratories of $\mathbf{J}$. Gilbard and L. Farris, to suggest that hyperosmolality of the tears is the primary mechanism for ocular surface damage in all forms of dry eye. ${ }^{45,57,86}$ Studies in the aqueous-deficient or meibomian-oil-deficient rabbit have demonstrated the evolution of squamous metaplasia and goblet cell loss in association with a rise in tear osmolality, ${ }^{87,88}$ and it has been shown that the hyperosmolar levels achieved in human NSDE are sufficient in vitro to damage rabbit corneal epithelial cells. ${ }^{89}$

Clinically, samples are taken from the lower tear meniscus and the referent value for the diagnosis of dry eye is $312 \mathrm{mosmol} / \mathrm{l}^{90}$ Some authorities have queried the likelihood that such hyperosmolar levels would be toxic to the ocular surface. However, it can be calculated that the preocular tear film, with a surface area of about $236 \mathrm{~mm}^{2},{ }^{91}$ offers a higher evaporative surface area than the meniscus, whose total surface area is in the region of $64 \mathrm{~mm}^{2}$ (assuming two menisci, a lid length of $40 \mathrm{~mm}$, and a radius of curvature of $0.4 \mathrm{~mm}$, occupying a third of a circle). This gives a ratio of areas of 3.7 and this would be expected to increase in dry eye, as tear meniscus volume falls. It would be anticipated, therefore, that the molality of the preocular film in the presence of dry eye would greatly exceed that of

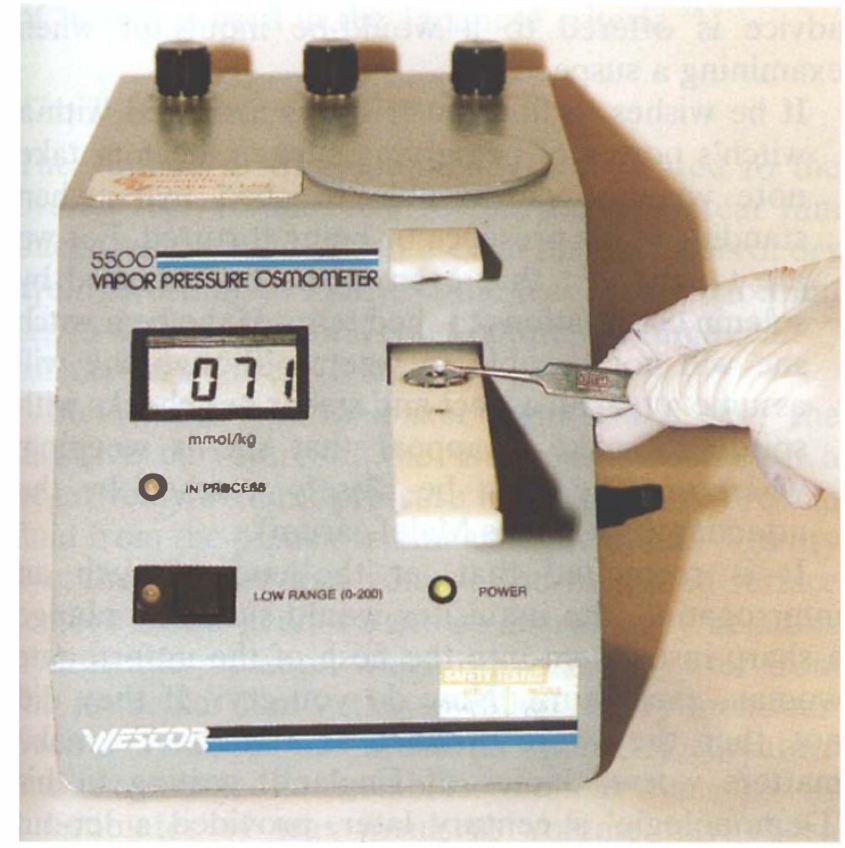

Fig. 6. Wescor vapour pressure osmometer. Insertion of a cellulose acetate disc wetted with tears. the meniscus, on which diagnostic measurements are habitually made.

Osmometric measurements are made on nanolitre samples taken from the lower meniscus and measured with a Clifton depression of freezing point osmometer. Samples are sealed under oil, and batchfrozen for later assay. The equipment is expensive and there are technical pitfalls relating to its use, which demand a high degree of skill. ${ }^{92,93}$ With this in mind we have been developing a simpler and less costly approach using a Wescor vapour-pressure osmometer, which can be used to make immediate measurements in the clinic. ${ }^{94,95}$ With this system, a cellulose acetate disc is saturated in tears from the lower conjunctival sac and rapidly inserted into a sealed chamber within which vapour pressure can be measured. The technique is quick and gives good agreement with the Clifton osmometer (Fig. 6). Since the method requires saturation of the paper disc there are still some problems in recording values in the most severe dry eye.

Another approach which we are developing involves the on-line measurement of tear conductivity, using a probe developed by Dr Marianne Fillenz in Oxford and Martin Boutelle of Imperial College. Tear conductivity is dependent on the number of dissolved ions in solution and is therefore an indicator of molality.

Fig. 7 shows the relationship between conductivity and sodium chloride concentration at different temperatures, measured with a conductivity probe over a range relevant to the tears. The response is graded, and there is a small linear variation with temperature for which adjustment will be made in the final, microprocessor-controlled instrument. At present, progress is being hindered by variable stability of the probe tip.

\section{Characterising Global Dry Eye}

As indicated earlier, other tests are required to move from a non-specific, global diagnosis to the characterisation of a tear-deficient or evaporative dry eye.

\section{Tear-Deficient Dry Eye}

Assessments of lacrimal function include the measurement of aqueous flow and volume and of proteins secreted by the lacrimal gland such as lysozyme and lactoferrin. Schirmer's test is the standard method for measuring aqueous flow.

\section{Schirmer's test}

The Schirmer I test without anaesthetic is a standard test of reflex tear secretion due to conjunctival stimulation. ${ }^{97}$ The careful study of van Bijsterveld ${ }^{96}$ reported a moderately high sensitivity and specificity using a referent value of $<6 \mathrm{~mm}$, but some reports 


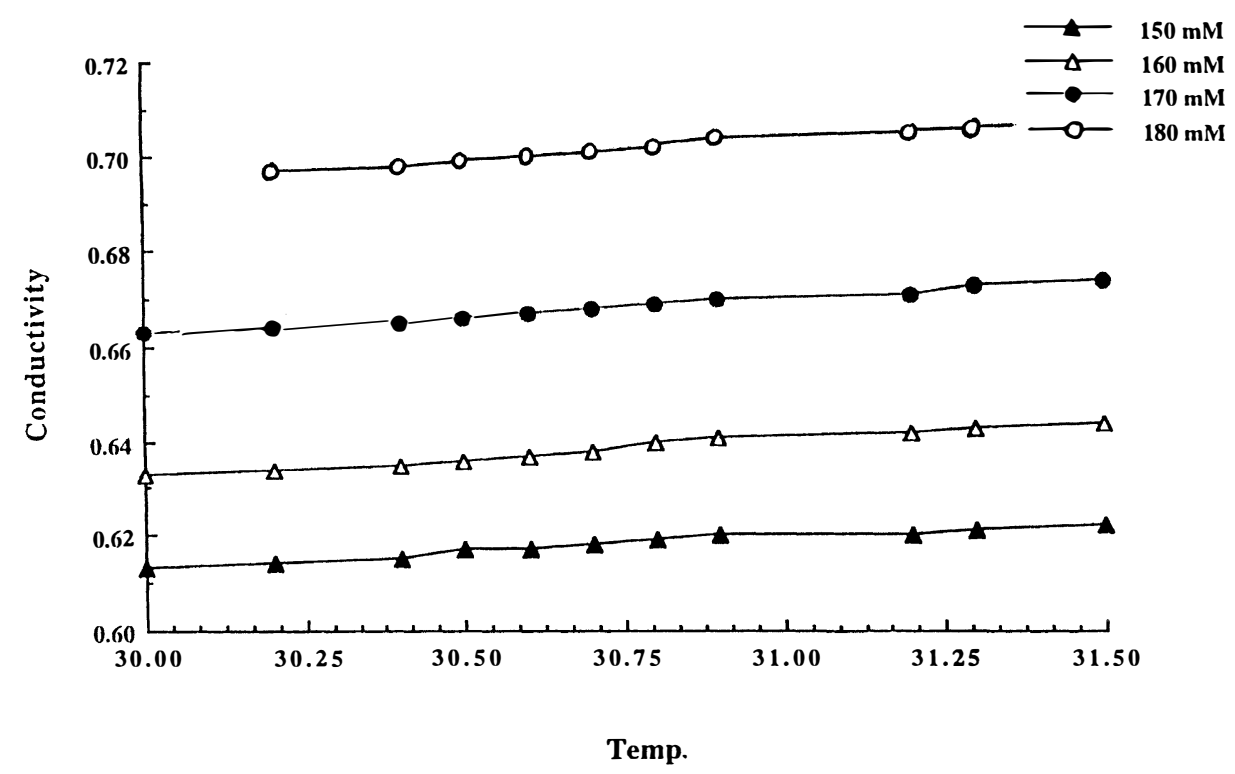

Fig. 7. Variation in electrical conductivity at different temperatures, in a series of sodium chloride solutions of differing molality. There is a small increase in conductivity with temperature in the range likely to be encountered at the preocular surface. (Courtesy of M. Fillenz and M. Boutielle.)

suggest that reliability is negatively influenced by evaporation, temperature and humidity. ${ }^{75}$ Holly and Esquivel $^{98}$ developed a kinetic version of the Schirmer test in which evaporation was minimised by placing the paper strip within a plastic sleeve. Serial measurements of wetting were used to construct a wetting curve from which the true secretory rate could be derived and the initial uptake of fluid from the tear $\mathrm{sac}^{99}$ could be ignored.

The Schirmer I test with anaesthetic has been said to be more accurate than the Schirmer I without anaesthetic but this is not confirmed in all reports. It gives a lower value than the test without anaesthetic and has been said to measure the basal tear secretion rate in the absence of a reflex component. ${ }^{66}$ However, this is now in doubt and it is likely that other sensory and psychological stimuli are operative. For instance, Gupta et al. ${ }^{100}$ have shown that nasal anaesthesia reduces the Schirmer I response by $34 \%$. Farris ${ }^{101}$ recommends using the test without anaesthetic when assessing patients for contact lens wear, in order to demonstrate an ability to generate reflex tears.

\section{The Schirmer Test with Nasal Stimulation (Schirmer II)}

The Schirmer II test assesses the accessibility of the lacrimal gland to reflex stimulation. The test was recently reintroduced by Tsubota et al. ${ }^{102}$ and Pflugfelder. ${ }^{103}$ The latter found that the response to nasal stimulation was lost in $100 \%$ of Sjögren syndrome patients and in only $30 \%$ of non-Sjögren dry eye patients (personal communication). Loss of reflex tearing was associated with maximum ocular surface staining scores with Bengal Rose. The test involves vigorous stimulation of the nasal mucosa and is unpleasant to perform.

It may be remarked as an aside, that the inability of painful stimuli to induce tearing in patients with Sjögren syndrome may have had unhappy consequences for such patients in the fifteenth century. In a tract (the Malleus Maleficarum-Witch's Hammer) written by two Dominican theologians, ${ }^{104,105}$ an account is given of the methods proposed for detection and management of witchcraft and sorcery at that time. In that document the following piece of advice is offered to a would-be inquisitor when examining a suspect:

If he wishes to find out if she is endowed with a witch's power of preserving silence, let him take note whether she is able to shed tears when standing in his presence or being tortured. For we are taught ... that even if she be exhorted by solemn conjurations to shed tears, if she be a witch she will not be able to weep: although she will assume a tearful aspect and smear her cheeks with spittle to make it appear that she is weeping; wherefore she must be closely watched by the attendants. (Malleus Maleficarum)

It is recounted that, at the end of such an interrogation, the inquisitor would suddenly plunge a sharp instrument into the flesh of the unfortunate woman, exclaiming, 'Now do you cry!' If they did not, then they were branded as a witch. To make matters worse, James of England, writing in his 'Demonologie' a century later, provided a let-out clause for unsuccessful inquisitors, warning them against the tears of the 'Crocodilia'. By such 
interrogations and interpretations, it appears that women were found guilty if they did not weep, but also if they did. These macabre reflections carry the wry implication that at this period many patients with Sjögren syndrome may have died at the stake because of this expression of their disease.

\section{Tear Volume}

Tear volume is an indirect measure of tear flow and falls as secretion falls. ${ }^{106}$ It is the loss of tear volume in tear-deficient dry eye that leads to ocular surface damage, since it is the evaporation from a diminished preocular pool which causes hyperosmolarity. Tsubota and Yamada ${ }^{107}$ have estimated that about $7.9 \%$ of the tears are lost by evaporation at normal secretory rates. They calculated, on the basis of the known fall in secretory rate in dry eye, that the same evaporation rate would represent at least $78 \%$ of the tear production and that even though, in their studies, evaporation decreased in their dry eye patients, still $47.5 \%$ of the tear production would be lost by evaporation.

Kurihashi et al. ${ }^{108}$ developed a Schirmer-like test in which the wetting of a length of thread is measured over a period of 15 seconds. The wetted length is an indicator of tear volume. This test has been adapted by Hamano and colleagues, ${ }^{109,110}$ who dyed the thread with the $\mathrm{pH}$-sensitive dye phenol red, so that the wetting can be observed more readily when the dye changes colour from yellow to orange in the alkaline tears. With a referent value of under $6 \mathrm{~mm}$, the test shows a lower inter-individual variation in normals than the Schirmer test with or without anaesthesia, and is reportedly better able to detect dry eye than the Schirmer test. ${ }^{111,112}$ A referent value of $10 \mathrm{~mm}$ is used in the Japanese criteria. ${ }^{53}$

\section{The Tear Meniscus}

The volume of the tear meniscus is related to the overall tear volume and to the preocular tear film thickness ${ }^{113}$ and has been used in the diagnosis of dry eye. According to Holly, ${ }^{114}$ the tear menisci account for $75-90 \%$ of the total tear volume. Mishima et al. ${ }^{106}$ calculated a lower volume $(1.5 \mu \mathrm{l})$.

McDonald and Brubaker ${ }^{115}$ indicated that the negative curvature of the meniscus was due to a negative hydrostatic pressure within it, which drew in fluid from the preocular film after the blink. ${ }^{115}$ In dry eye, the reduced tear volume and increased surface tension of the tears causes an increasingly negative hydrostatic pressure, which draws more water from the preocular film - the so-called thirsty meniscus. Such a meniscus has a shorter radius of curvature and is construed to destabilise the tear film.

Estimates of tear meniscus volume have been based on fluorimetry, or measurement of the height of the fluorescein-stained meniscus with optical magnification and a graticule. ${ }^{116-120}$ More recently measurements have been made by image analysis of a slit profile of the meniscus. ${ }^{85,121}$ Table IV lists the values achieved by these different methods, which show considerable variation. Problems of measurement relate to the difficulty of measuring the edge of an asymptotic curve (the upper edge of the meniscus) when measuring height, stimulation of tears by the illumination source, and expansion of the tear reservoir by the instillation of fluorescein $(1 \mu \mathrm{l})^{116}$ - an effect which, however, is said to be lost after 4-7 minutes. ${ }^{122}$ The slit image system is highly reproducible and, although time-consuming, has made it possible to measure tear meniscus height (TMH), curvature (TMC), width and cross-sectional areas. ${ }^{85}$

The studies of Mainstone et al. ${ }^{121}$ have shown that TMH correlates strongly with the phenol red test, NIBUT, staining of the ocular surface by fluorescein and Rose Bengal $(p<0.01)$. Only the TMH correlated with the McMonnies' symptom score. The TMC correlated with all but the Schirmer test. TMH and TMC were of similar diagnostic accuracy (with a referent value of $0.35 \mathrm{~mm}$ for each), but TMH was the best predictor of dry eye in this small study (15 normal; 15 age-matched dry eyes). TMH and TMC were better predictors of dry eye than the Schirmer I test, but less good than the Bengal Rose staining. Bengal Rose and fluorescein staining were correlated.

\section{Meniscometry}

We have recently developed a non-invasive method for measuring tear meniscus curvature which we call meniscometry. Like keratometry, it is based on the reflection of an illuminated target from the mirrorlike surface of the tear film, in this case using the surface of the meniscus as a concave mirror (Fig. 8). Using this technique we have been able to image the meniscus, estimate its radius of curvature and obtain morphological and dynamic information over a period of time using photography and an on-line video-system. ${ }^{123}$ We are currently developing the technique as a simple diagnostic test for dry eye and for the investigation of tear kinetics (Fig. 9).

\section{Evaporative Dry Eye}

Many of the tests described above relate only to the diagnosis of tear-deficient dry eye. The tests which follow relate to evaporative dry eye. The two forms

Table IV. Tear meniscus height in normals

\begin{tabular}{lcc}
\hline Author & Date & Mean height $(\mathrm{mm})$ \\
\hline Jordan and Baum $^{116}$ & 1980 & 0.3 \\
Lamberts $^{117}$ & 1983 & $0.23(0.1-0.6)$ \\
Guillon $^{118}$ & 1988 & 0.41 \\
Port and Asaria $^{119}$ & 1990 & 0.18 \\
Jaanus $^{120}$ & 1990 & 0.5 \\
Maistone et al. $^{121}$ & 1996 & $0.46( \pm 0.173)$ \\
\hline
\end{tabular}




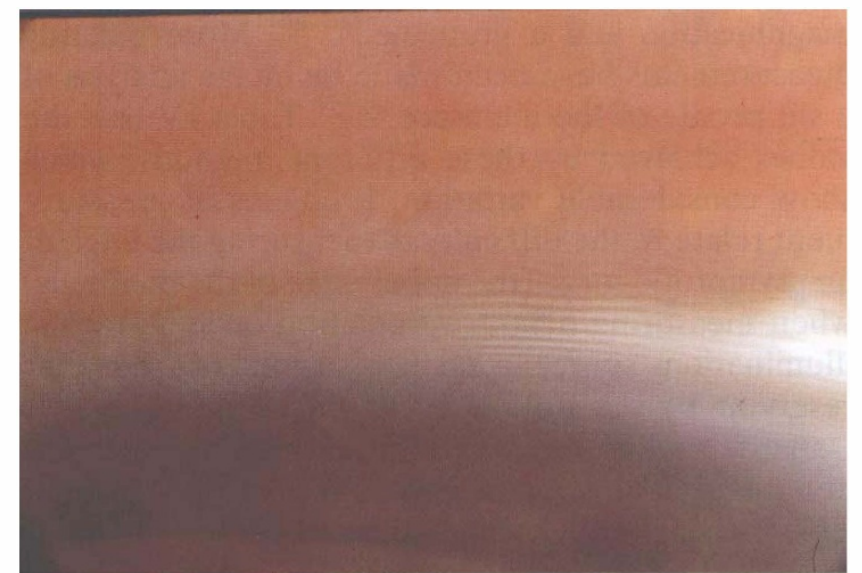

Fig. 8. Meniscometry: reflection of a horizontally striped target from the lower tear meniscus. The air-tear interface acts as a concave mirror. The radius of curvature of the meniscus can be calculated from the image size, assuming the curvature to approximate to the section of a sphere.

of dry eye are not mutually exclusive and it has been estimated that meibomian gland disease is encountered in about $30 \%$ of those who present with aqueous-deficient dry eye. ${ }^{124}$ Mathers ${ }^{63}$ has shown that the degree of tear hyperosmolarity is increased when these two forms of dry eye coincide.

Although it is relatively easy to identify the presence of obstructive oil gland disease in a given patient, it is less easy to confirm that it is responsible for an evaporative dry eye. Precise diagnosis requires the demonstration of increased evaporation from the surface of the eye in the presence of normal aqueous tear secretion and quality, and the technique of

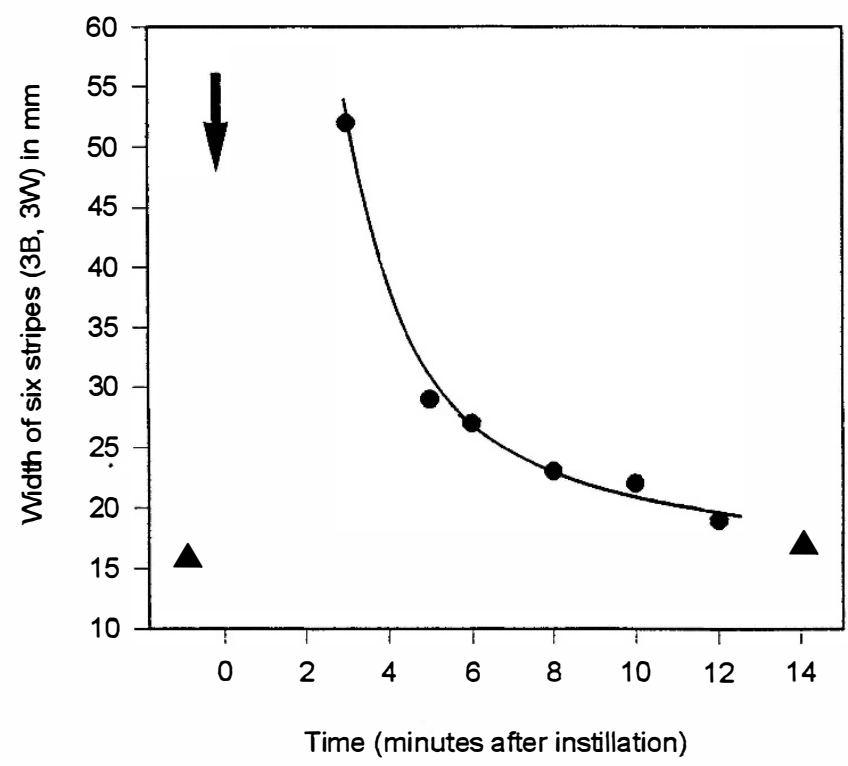

Fig. 9. Using meniscometry to follow the kinetics of drop delivery. Ordinate: image width of stripes in arbitary units. Abscissa: time in minutes. The radius of curvature of the meniscus is increased by instillation of a drop of Celluvisc, and decreases over time as the meniscus drains. evaporimetry is available in only a limited number of clinics.

However, obstructive meibomian gland disease is the major source of evaporative dry eye and there are now several methods available for its diagnosis (Table V). Tear film lipid thickness is assumed to influence the evaporation rate, which has been measured by several groups, using interferometry. The state of the meibomian glands can also be measured by a number of techniques. The simplest of these involves the quantification of occluded meibomian orifices and grading of the expressibility and quality of the expressed meibomian oil. ${ }^{59,60}$ The latter may vary from clear to an opaque toothpastelike consistency. Mathers uses the transillumination technique of infrared meibography to demonstrate gland drop out ${ }^{125,126}$ and we use the technique of meibometry to measure the level of lid oil on the lid margin. ${ }^{12,13}$

\section{The Sequence of Testing}

The diagnosis of dry eye is based on the results of a group of tests which it may be necessary to perform in the clinic at a single visit, although repetition may be required for confirmation. It is important for tests to be carried out in the correct sequence and at the appropriate intervals, in order to avoid one test interfering with another. At present there are not adequate data on which to base the intervals selected.

A suggested sequence for the tests is as follows: ${ }^{127}$ Tear sampling, if planned (e.g. for lactoferrin or for the measurement of osmolality) should be done first, and, to allow for tear stimulation, an interval should be left before assessing tear stability. Tear stability can be measured non-invasively as the NIBUT, or invasively, with fluorescein, as the FBUT. For the latter, fluorescein is instilled into each eye (see above), after which the staining pattern at the surface of the globe can then be graded. Since instillation of fluorescein will change the volume of fluorescein in the tear sac, a further period must be allowed, for drainage. The Schirmer test can now be performed. Finally, if it is intended to grade ocular surface damage by an alternative method to fluorescein (e.g. with Bengal Rose or Lissamine Green), this may now be carried out without interval. Use of the Schirmer paper itself damages the ocular surface, but the

Table V. Assessing meibomian gland function

Grading glands and orifices
Grading expression and quality
Meibometry.
Casual levels
Delivery
Meibography: gland drop-out
Interferometry: tear film thickness
Evaporimetry


pattern is clearly distinguishable from damage due to dry eye. We are currently using meniscometry to estimate the optimum intervals between critical elements of the tests.

\section{THERAPY FOR DRY EYE}

Tear substitutes have been the mainstay of therapy over the years but we are increasingly assisted by approaches which will conserve the tears and we may anticipate further help in the future from improved delivery systems.

\section{Formulation}

In recent years there has been close attention to formulation. Edelhauser has shown that an alkaline $\mathrm{pH}$, achieved by the inclusion of bicarbonate, has a beneficial effect on epithelial permeability. ${ }^{128}$ Gilbard $^{129}$ introduced the use of the hypotonic tear substitute to combat hyperosmolarity, and more recently, by modifying electrolyte composition, has developed a tear substitute which is effective in reversing the clinical and structural features of dry eye. 57,129

The introduction of non-Newtonian tear substitutes (such as hyaluronate and polyacrylic acid) has provided agents with a viscosity which would not be tolerated in a Newtonian fluid such methyl cellulose. These agents thicken and stabilise the tear film when the eye is static and because of the occurrence of shear-thinning during the blink or saccade, they can be designed to limit the symptoms of viscous drag while maximising their stabilising effect. ${ }^{130}$

Another approach has been to combine glycerol, as a water-retaining humectant, with hyaluronic acid. This has shown an improvement in both symptoms and Bengal Rose staining in a recent clinical trial by Solomons et al. ${ }^{131}$

What has been new in recent years has been the attempt to include active principles in tear substitutes, directed at several different targets.

A strong case has been put forward to suggest that circulating androgens are essential for the maintenance of lacrimal function and that a loss of bioavailable androgen is an important trigger to the process of lymphocyte infiltration in both Sjögren and non-Sjögren aqueous-deficient dry eye. It has been suggested that androgen replacement or topical supplementation would afford a rational therapeutic option. ${ }^{132,133}$

There is evidence that the reduced tear secretion in aqueous-deficient dry eye is due in part to a functional block in lacrimal secretion and not entirely to glandular destruction. One proposal is that cytokines and peptidergic mediators secreted by infiltrating lymphocytes could block neurotransmission to the lacrimal gland. ${ }^{133}$ This implies the possibility of stimulating tear production by over- riding or removing the block. Gilbard et al. ${ }^{134}$ have shown the feasibility of stimulating residual lacrimal gland function with topical IBMX (isobutyl methyl xanthine) in human studies. IBMX is an inhibitor of phosphodiesterase which can therefore amplify cAMP within the acinus. Kiang et al. ${ }^{135}$ have reported on the value of systemic pilocarpine in the treatment of dry eye.

Recently Kaswan and others ${ }^{136-140}$ have shown that topical cyclosporin A can greatly improve the clinical and morphological state in canine dry eye, acting on both lacrimal gland and conjunctival function. These results have been echoed to a lesser degree in the recently reported human studies in Sjögren and non-Sjögren dry eye. ${ }^{141,142}$

\section{Preservative-Free Substitutes}

Not least of the improvements which have been achieved in recent years has been the development of preservative-free preparations. There are some who advocate their use in all dry eye patients, but this counsel of perfection would appear to be unnecessary in patients with milder symptoms which are relieved by cheaper, standard commercial preparations. At the same time research is being conducted into the development of safer preservatives, using corneal epithelial cells in culture as a test bed for toxicity, ${ }^{143,144}$ or devices which will extract the preservative from the drop at the moment of delivery. ${ }^{145}$

\section{Conservation}

Conservation of tears can be achieved by punctal occlusion and by provision of protective spectacles. Everst Harris spectacles provide occlusive side pieces that can be custom made in an optometry department. Alternatively stick-on side pieces are available commercially in some countries (Eagle Vision). The subject of occlusion has been reviewed by Lamberts. ${ }^{146}$ Gelatin and collagen plugs serve the purpose of estimating benefit and the risk of overflow. Silicone plugs provide a longer period of occlusion and occlusion can be extended with the use of intracanalicular cyanoacrylate or by surgical means, and there are surgical approaches aside from cautery, such as Murube-del-Castillo's reversible, dry docking technique. ${ }^{147}$

\section{Delivery}

There are now several reports and patents related to devices for the automated semi-continuous delivery of fluids, including tear substitutes, to the eye. ${ }^{148}$ This re-discovers an approach originally developed by Dohlman in Boston. ${ }^{149}$ We have been working on the development of a forced flow system which will deliver a $5 \mu$ l stream of drops to the eye within the onset of a blink. ${ }^{150}$ This principle will be 
incorporated in cap-like containers from which fluid will be jetted mechanically.

Lemp ${ }^{151}$ has discussed an approach to the staging of treatments according to the severity of the dry eye.

\section{CONCLUSIONS}

I hope that it is apparent from this review that the field of research into the tears and dry eye is a very active one. There have been major strides in the development of new and effective therapies and we are already reaping the harvest of these new approaches.

Thanks are due to the staff of the Nuffield Laboratory Oxford, and in particular Dr John Tiffany, for support and instruction over the years and for help in the preparation of this manuscript, and to Professor Dan Robinson of George Washington University for drawing my attention to the Malleus Maleficarum.

Key words: Dry eye, KCS, Sjögren syndrome, meibomian obstruction.

\section{REFERENCES}

1. Catford GV. Our founder, Robert Doyne. A short biographical tribute. Trans Ophthalmol Soc UK 1976;96:285-9.

2. Doyne RW. A description of a form of conjunctivitis. Trans Ophthalmol Soc UK 1910;30:85-90.

3. Wolffe E. The muco-cutaneous junction of the lid margin and the distribution of the tear fluid. Trans Ophthalmol Soc UK 1946;66:291-308.

4. Bron AJ. Prospects for the dry eye. The Duke Elder Lecture. Trans Ophthalmol Soc UK 1985;104: 801-26.

5. Chung CW, Tigges M, Stone RA. Peptidergic innervation of the primate meibomian gland. Invest Ophthalmol Vis Sci 1996;37:238-45.

6. Ruskell G. Facial parasympathetic innervation of the choroidal blood vessels in monkeys. Exp Eye Res 1971;12:166-72.

7. Sullivan DA, Wickham LA, Toda I, Gao J. Identification of androgen, estrogen and progesterone receptor mRNAs in rat, rabbit and human ocular tissues [abstract 2980]. Invest Ophthalmol Vis Sci (ARVO Suppl) 1995;35:S651.

8. Linton RG, Curnow DH, Riley WJ. The meibomian glands: an investigation into the secretion and some aspects of the physiology. Br J Ophthalmol 1961;45: 718-23.

9. McDonald JE. Surface phenomena of tear films. Trans Am Ophthalmol Soc 1968;66:905-9.

10. Bron AJ. Control of meibomian secretion and its role in ocular surface disease. Castroviejo Lecture, Chicago. American Academy of Ophthalmology, November 1993.

11. Chew CKS. Quantifying meibomian lipid on the human lid margin. MSc thesis, University of Oxford, Oxford.

12. Chew CKS, Jansweijer C, Tiffany JM, Dikstein S, Bron AJ. An instrument for quantifying meibomian lipid on the lid margin: the Meibometer. Curr Eye Res 1993;12:247-54.

13. Chew CKS, Hykin PG, Jansweijer C, Dikstein S, Tiffany JM, Bron AJ. The casual level of meibomian lipids in humans. Curr Eye Res 1993;12:255-9.
14. Norn M. Expressibility of meibomian secretion: relation to age, lipid precorneal film, scales, foam, hair and pigmentation. Acta Ophthalmol (Copenh) 1987;65:137-42.

15. Tiffany JM, Chew CKS, Bron AJ, Quinlan M. Availability of meibomian oil and thickness of the oil layer on the precorneal tear film [abstract 592]. Invest Ophthalmol Vis Sci (ARVO Suppl) 1993;34:821.

16. Chew CKS, Hykin PG, Jansweijer C, Dikstein S, Tiffany JM, Bron AJ. The casual level of meibomian lipids in humans. Curr Eye Res 1993;12:255-9.

17. Holly FJ. Formation and rupture of the tear film. Exp Eye Res 1973;15:515-25.

18. Norn MS. External eye: methods of examination. 2nd ed. Scriptor, 1983.

19. Dartt DA. Regulation of inositol phosphates, calcium and protein kinase $\mathrm{C}$ in the lacrimal gland. Prog Retinal Eye Res 1994;13:443-78.

20. Seifert P, Spitznas M. Demonstration of nerve fibers in human accessory lacrimal glands. Graefes Arch Clin Exp Ophthalmol 1994;232(2):107-114.

21. Jones LT. The lacrimal secretory system and its treatment. Am J Ophthalmol 1966;62:47-60.

22. Jordan A, Baum J. Basic tear flow. Does it exist? Ophthalmology 1980;87:920.

23. Gupta A, Heigle TJ, Pflugfelder SC. Nasolacrimal stimulation of aqueous tear production [abstract 3936]. Invest Ophthalmol Vis Sci (ARVO Suppl) 1996;37:S851.

24. Nichols BA, Chiappino ML, Dawson CR. Demonstration of the mucus layer of the tear film by electron microscopy. Invest Ophthalmol Vis Sci 1985;26: 464-73.

25. Kessing SV. Mucous gland system of the conjunctiva: a quantitative normal anatomical study. Acta Ophthalmol Suppl 1968;95:1-133.

26. Holly FJ, Lemp MA. Wettability and wetting of corneal epithelium. Exp Eye Res 1971;11:239-50.

27. Tiffany JM, Winter N, Bliss G. Tear film stability and tear surface tension. Curr Eye Res 1989;8:507-15.

28. Greiner JV, Weidman TA, Korb DR, Allansmith MR. Histochemical analysis of secretory vesicles in non-goblet conjunctival epithelial cells. Acta Ophthalmol (Copenh) 1985;63:89-92.

29. Watanabe T, Fabricant M, Tisdale AS, SpurrMichaud SJ, Lindberg K, Gipson IK. Human corneal and conjunctival epithelia produce a mucin-like glycoprotein for the apical surface. Invest Ophthalmol Vis Sci 1995;36:337-44.

30. Inatomi T, Spurr-Michaud S, Tisdale AS, Zhan Q, Feldman ST, Gipson IK. Expression of secretory mucin genes by human conjunctival epithelia. Invest Ophthalmol Vis Sci 1996;37:1684-92.

31. Gipson IK, Inatomi T. Mucin genes expressed by the ocular surface epithelium. Prog Retinal Eye Res 1997;16:81-98.

32. Bolis S, Ball M, Devine P, Morris C. Mucin species in the human tear film [abstract 3903]. Invest Ophthalmol Vis Sci (ARVO Suppl) 1996;37:S846.

33. Sack RA, Bogart B, Sathe S, Beaton A, Lew G. Characterisation and origin of major non-reducing HMW tear sialoglycoproteins [abstract 3906]. Invest Ophthalmol Vis Sci (ARVO Suppl) 1996;37:S846.

34. Ellingham RB, Berry M, Corfield AP. Agarose gel electrophoresis of human tears; mucin detected [abstract 3902]. Invest Ophthalmol Vis Sci (ARVO Suppl) 1996;37:S845. 
35. Tiffany JM, Pandit JC, Bron AJ. Soluble mucins and the physical properties of tears [abstract 3901]. Invest Ophthalmol Vis Sci (ARVO Suppl) 1996;37:S845.

36. Holly FJ, Lemp MA. Tear physiology and dry eyes: review. Surv Ophthalmol 1977;22:69-87.

37. Cope C, Dilly PN, Kaura R, Tiffany JM. Wettability of the corneal surface: a reappraisal. Curr Eye Res 1986;5:777-85.

38. Liotet S, Van Bijsterveld OP, Kogbe O, Laroche L. A new hypothesis on tear film stability. Ophthalmologica 1987;195:119-24.

39. Tiffany JM. The viscosity of human tears. Int Ophthalmol 1991;15:371-6.

40. Kuizenga A, van Haeringen NJ, Meijer F, Kilstra A. Analysis of human tear fluid components inhibiting protein adhesion to plastic surfaces. Exp Eye Res 1996;63:319-28.

41. Tiffany JM, Pandit JC, Bron AJ. Soluble mucins and the physical properties of tears [abstract 3901]. Invest Ophthalmol Vis Sci (ARVO Suppl) 1996;37:S845.

42. Bogart BI, Lew G, Sathe S, Sack R. Surface active proteins [abstract 3907]. Invest Ophthalmol Vis Sci (ARVO Suppl) 1996;37:S846.

43. Lemp MA. Report of the National Eye Institute/ Industry workshop on clinical trials in dry eyes. CLAO J 1995;21:221-32.

44. Gilbard JP, Farris RL, Santa Maria J. Osmolarity of tear microvolumes in keratoconjunctivitis sicca. Arch Ophthalmol 1978;96:677-81.

45. Gilbard JP, Farris RL. Tear osmolarity and ocular surface disease in keratoconjunctivitis sicca. Arch Ophthalmol 1979;97:1642-6.

46. Gilbard JP. Human tear film electrolyte concentrations in health and dry-eye disease. In: Smolin G, Friedlaender $\mathrm{MH}$, editors. International ophthalmology clinics. Dry eye. 1st ed. Boston, Mass: Little, Brown, 1994:27-36.

47. Subcommittee for Scleroderma Criteria of the American Rheumatism Association Diagnostic and Therapeutic Criteria Committee. Preliminary criteria for the classification of systemic sclerosis (scleroderma). Arthritis Rheum 1980;23:581-90.

48. Tan EM, Cohen AS, Fries JF, Masi AT, McShane DJ, Rothfield NF, Schaller JG, Talal N, Winchester RJ. The 1982 revised criteria for the classification of systemic lupus erythematosus. Arthritis Rheum 1982;25:1271-7.

49. Arnett FC, Edworthy SM, Bloch DA, McShane DJ, Fries JF, Cooper NS, Healey LA, Kaplan SR, Liang MH, Luthra HS, Medsger TA, Jr, Mitchell DM, Neustadt DH, Pinals RS, Schaller JG, Sharp JT, Wilder RL, Hunder GG. The American Rheumatism Association 1987 revised criteria for the classification of rheumatoid arthritis. Arthritis Rheum 1988;31: 315-24.

50. Manthorpe R, Oxholm P, Prause JU, Schiöde M. The Copenhagen criteria for Sjögren's syndrome. Scand J Rheumatol Suppl 1986;61:19-21.

51. Fox RI. Summary of the third international Sjögren's syndrome symposium. Arthritis Rheum 1991;34: 1617-8.

52. Vitali C, Bombardieri S, Moutsopoulos HM, Balestrieri G, Bencivelli W, Bernstein RM, Bjerrum KB, Braga S, Coll J, de Vita S, et al. Preliminary criteria for the classification of Sjögren's syndrome: results of a prospective concerted action supported by the European Community. Arthritis Rheum 1993;36: $340-7$.
53. Shimazaki J. Definition and criteria of dry eye. Report of the Dry Eye Research/Diagnostic Standards Committee. Ophthalmology (Japan) 1995;37:765-70.

54. Gratwhol AA, Moutsopoulos HM, Chused TM, Akizuki M, Wolf RO, Sweet JB, Beisseroth AB. Sjögren's-type syndrome after allogeneic bone-marrow transplantation. Ann Intern Med 1977;87:703-6.

55. Hirst LW, Jabs DA, Tutschka PJ, Green WR, Santos GW. The eye in bone marrow transplantation. I. Clinical study. Arch Ophthalmol 1983;101:580-4.

56. Lucca A, Farris RL, Bielory L, Caputo AR. Keratoconjunctivitis sicca in male patients infected with human immunodeficiency virus type 1 . Ophthalmology 1990;97:1008-10.

57. Gilbard JP. Dry eye disorders. In: Albert DM, Jakobiec FA, editors. Principles and practice of ophthalmology. Philadelphia: WB Saunders, 1994: 257-76.

58. Gilbard JP, Gray KL, Rossi SR. A proposed mechanism for increased tear-film osmolarity in contact lens wearers. Am J Ophthalmol 1986;102: 505-7.

59. Bron AJ, Benjamin L, Snibson GR. Meibomian gland disease: classification and grading of lid changes. Eye 1991;5:395-411.

60. Mathers WD, Shields WJ, Sachdev MS, Petroll WM, Jester JV. Meibomian gland dysfunction in chronic blepharitis. Cornea 1991;10:277-85.

61. Vold SD, Carroll RP, Nelson JD. Dermatochalasis and dry eye: a surgically treatable syndrome. Am J Ophthalmol 1993;115:216-20.

62. Rolando M, Refojo MF. Tear evaporimeter for measuring water evaporation rate from the tear film under controlled conditions in humans. Exp Eye Res 1983;36:25-33.

63. Mathers WD. Ocular evaporation in meibomian gland dysfunction and dry eye. Ophthalmology 1993;100: 347-51.

64. McCulley JP, Sciallis GF. Meibomian keratoconjunctivitis. Am J Ophthalmol 1977;84:788-93.

65. McMonnies CW, Ho A. Patient history in screening for dry eye conditions. J Am Optom Assoc 1987;58:296-301.

66. McMonnies CW, Ho A. Responses to a dry eye questionnaire from a normal population. J Am Optom Assoc 1987;58:588-91.

67. Schein OD, Tielsch JM, Muñoz B, Bandeen-Roche K, West S. Relationship between signs and symptoms of dry eye: a population-based perspective. Submitted.

68. Feenstra RPC, Tseng SCG. What is actually stained by rose bengal? Arch Ophthalmol 1992;110:984-93.

69. Norn MS. Lissamine green. Vital staining of cornea and conjunctiva. Acta Ophthalmol (Copenh) 1973;51:483-91.

70. Eliason AJ, Maurice DM. Staining of the conjunctiva and conjunctival tear film. $\mathrm{Br} \mathrm{J}$ Ophthalmol 1990;74:519-22.

71. Norn MS. Vital staining of cornea and conjunctiva. Acta Ophthalmol Scand 1962;40:389-401.

72. Norn MS. Dead, degenerate, and living cells in conjunctival fluid and mucous thread. Acta Ophthalmol Scand 1969;47:1102-15.

73. Feenstra RPG, Tseng SCG. Comparison of fluorescein and rose bengal staining. Ophthalmology 1992;99:605-17.

74. Watanabe $H$, Tanaka M. Rose bengal staining and expression of a mucin-like glycoprotein in corneal epithelium [abstract 1649]. Invest Ophthalmol Vis Sci (ARVO Suppl) 1996;37:S357. 
75. van Bijsterveld OP. Diagnostic tests in the sicca syndrome. Arch Ophthalmol 1969;82:10-4.

76. Solomons A, Merin S. The effect of a new tear substitute containing glycerol and hyaluronate on keratoconjunctivitis sicca. Submitted.

77. Bron AJ, Mangat H, Quinlan M, Foley-Nolan A, Eustace P, Fsadni M, Sunderraj P. Polyacrylic acid gel tears in patients with dry eyes: a randomised comparison with polyvinylalcohol. Submitted.

77. Bron AJ, Tiffany JM, Yokoi N, Banerjee G, Brown NAP. Meniscometry: a new method to measure tear meniscus curvature [abstract]. Invest Ophthalmol Vis Sci (ARVO Suppl) 1997;38:5151.

78. Pflugfelder SC, Huang AJW, Schuchovski PT, et al. Cytological features of primary Sjögren syndrome. Ophthalmology 1990;97:985-91.

79. Norn MS. Desiccation of the precorneal film. I. Corneal wetting time. Acta Ophthalmol (Copenh) 1969;47:865-80.

80. Lemp MA, Hamill JR. Factors affecting tear film breakup in normal eyes. Arch Ophthalmol 1973;89:103-5.

81. Mengher LS, Bron AJ, Tonge SR, Gilbert DJ. A noninvasive instrument for clinical assessment of the precorneal tear film stability. Curr Eye Res 1985;4:1-7.

82. Mengher LS, Bron AJ, Tonge SR, Gilbert DJ. Effect of fluorescein instillation on the pre-corneal tear film stability. Curr Eye Res 1985;4:9-12.

83. Farrell J, Grierson DJ, Patel S, Sturrock RD. A classification for dry eyes following comparison of tear thinning time with Schirmer tear test. Acta Ophthalmol Scand 1992;70:357-60.

84. Craig JP, Blades K, Patel S. Tear lipid layer structure and stability following expression of the meibomian glands. Ophthalmic Physiol Opt 1995;15:569-74.

85. Golding TR, Bruce AS, Mainstone JC. The relationship between tear meniscus parameters and tear film stability. In press.

86. Gilbard JP, Farris RL. Ocular surface drying and tear film osmolarity in thyroid eye disease. Acta Ophthalmol (Copenh) 1983;61:108-16.

87. Gilbard JP, Rossi SR, Gray KL, Hanninen LA, Kenyon KR. Tear film osmolarity and ocular surface disease in two rabbit models for keratoconjunctivitis sicca. Invest Ophthalmol Vis Sci 1988;29:374-8.

88. Gilbard JP, Rossi SR, Heyda KG. Tear film and ocular surface changes after closure of the meibomian gland orifices in the rabbit. Ophthalmology 1989;96:1180-6.

89. Gilbard JP, Carter JB, Sang DN, Refojo MF, Hanninen LA, Kenyon KR. Morphologic effect of hyperosmolarity on rabbit corneal epithelium. Ophthalmology 1984;91:1205-12.

90. Gilbard JP, Farris RL, Santa Maria J. Osmolarity of tear microvolumes in keratoconjunctivitis sicca. Arch Ophthalmol 1978;96:677-81.

91. Tiffany JM, Todd BS, Baker MR. Computer-assisted calculation of exposed area of the human eye. In: Sullivan DA, editor. Lacrimal gland, tear film, and dry eye syndromes: basic science and clinical relevance. New York: Plenum Press (in press).

92. White KM, Benjamin W J, Hill RM. Human basic tear fluid osmolality. I. Importance of sample collection strategy. Acta Ophthalmol (Copenh) 1993;71:524-9.

93. White KM, Benjamin WJ, Hill RM. Human basic tear fluid osmolality. II. Importance of processing strategy. Acta Ophthalmol (Copenh) 1993;71:530-8.
94. Tiffany JM, Chew CKS, Bron AJ. Vapour pressure osmometry of human tears [abstract 2031]. Invest Ophthalmol Vis Sci (ARVO Suppl) 1994;35:1692.

95. Anagnoste SR, Hall LS, Lisman RD. Vapor pressure osmolarity of tears as a clinical tool for evaluation of keratoconjunctivitis sicca [abstract 3941]. Invest Ophthalmol Vis Sci (ARVO Suppl) 1996;37:S852.

96. van Bijsterveld OP. A simple test for lacrimal gland function: a tear lactoferrin assay by radial immunodiffusion. Graefes Arch Clin Exp Ophthalmol 1983; 7:71-81.

97. Schirmer O. Studien zur Physiologie und Pathologie der Tränenabsonderung und Tränenabfuhr. Graefes Arch Klin Exp Ophthalmol 1903;56:197-291.

98. Holly FJ, Esquivel ED. Lacrimation kinetics in humans as determined by a novel technique. In: Holly FJ, editor. The preocular tear film. Lubbock: Dry Eye Institute, 1986:76-88.

99. Clinch TE, Benedetto DA, Felberg NT, Laibson PR. Schirmer's test: a closer look. Arch Ophthalmol 1983;101:1383-6.

100. Gupta A, Heigle TJ, Pflugfelder SC. Nasolacrimal stimulation of aqueous tear production [abstract 3936]. Invest Ophthalmol Vis Sci (ARVO Suppl) 1996;37(3):S851.

101. Farris RL. Contact lenses and the dry eye. In: Smolin $\mathrm{G}$, Friedlander $\mathrm{MH}$, editors. International ophthalmology clinics: dry eye. 1st ed. Boston, Mass: Little, Brown, 1994: 129-36.

102. Tsubota K. The importance of the Schirmer test with nasal stimulation [letter]. Am J Ophthalmol 1991; 111:106-8.

103. Pflugfelder S. Personal communication.

104. Kramer H, Sprenger J. The Malleus Maleficarum [transl Summers M]. 1st ed. New York: Dover, 1971.

105. Robinson D. Wild beasts and idle humours. Boston, Mass: Harvard University Press, 1996.

106. Mishima S, Gasset A, Klyce S, Baum J. Determination of tear volume and tear flow. Invest Ophthalmol 1966;5:264-76.

107. Tsubota K, Yamada M. Tear evaporation from the ocular surface. Invest Ophthalmol Vis Sci 1992;33: 2942-50.

108. Kurihashi K, Yanagihara N, Honda Y. A modified Schirmer test: the fine-thread method for measuring lacrimation. J Pediatr Ophthalmol 1977;14:390-8.

109. Hamano H, Hori M, Hamano T, Mitsunaga S, Maeshima J, Kojima S, Kawabe H, Hamano T. A new method for measuring tears. CLAO J 1983;9:281-9.

110. Hamano T. The clinical significance of the phenol red thread tear test. Folia Ophthalmol Jpn 1991;42: 719-27.

111. Asbell PA, Chiang B, Li K. Phenol-red thread test compared to Schirmer test in normal subjects. Ophthalmology (Suppl) 1987;94:128.

112. Chiang B, Asbell PA, Franklin B. Phenol-red thread test and Schirmer test for tear production in normal and dry eye patients. Invest Ophthalmol Vis Sci (ARVO Suppl) 1988;29:337.

113. Creech JL, Do L, Fatt I, Radke CJ. Measuring tearfilm thickness: individual variations and implications for tear-film stability [abstract]. In: Second international conference on the lacrimal gland, tear film and dry eye syndromes: basic science and clinical relevance. Bermuda, 16-19 November 1996.

114. Holly FJ. Dry eye and the Sjögren's syndrome. Scand J Rheumatol Suppl 1986;61:201-5. 
115. McDonald JE, Brubacker S. Meniscus-induced thinning of tear films. Am J Ophthalmol 1971;72:139-46.

116. Jordan A, Baum J. Basic tear flow. Does it exist? Ophthalmology 1980;87:920.

117. Lamberts DW. Keratoconjunctivitis sicca. In: Smolin $\mathrm{G}$, Thoft RA, editors. The cornea: scientific foundations and clinical practice. 1st ed. Boston, Mass: Little, Brown, 1983:293-309.

118. Guillon JP. Normative tear film characteristics [abstract]. Am J Optom Physiol Opt 1988;65 (Suppl):76.

119. Port MJA, Asaria TS. Assessment of human tear volume. J Br Contact Lens Assoc 1990;13:76-82.

120. Jaanus S. Focus on pharmacology. I. Managing the dry eye. Clin Eye Vis Care 1990;2:38-44.

121. Mainstone JC, Bruce AS, Golding TR. Tear meniscus measurement in the diagnosis of dry eye. Curr Eye Res 1996;15:653-61.

122. Lim KJ, Lee JH. Measurement of the tear meniscus height using $0.25 \%$ fluorescein sodium. Korean J Ophthalmol 1991;5:34-36.

123. Bron AJ, Tiffany JM, Yokoi N, Banerjee G, Brown NAP. Meniscometry: a new method to measure tear meniscus curvature [abstract]. Invest Ophthalmol Vis Sci (ARVO Suppl) 1997;38:5151.

124. McCulley JP. Meibomitis. In: Kaufman HE, Barron BA, McDonald MB, Waltman SR, editors. The cornea. New York: Churchill Livingstone, 1988: 125-37.

125. Jester JV, Rife L, Nii D, Luttrull JK, Wilson L, Smith RE. In vivo biomicroscopy and photography of meibomian glands in a rabbit model of meibomian gland dysfunction. Invest Ophthalmol Vis Sci 1982;22:660-7.

126. Robin JB, Jester JV, Nobe J, Nicolaides N, Smith RE. In vivo transillumination biomicroscopy and photography of meibomian gland dysfunction: a clinical study. Ophthalmology 1985;92:1423-6.

127. Bron AJ. Non-Sjögren dry eye: pathogenesis and diagnosis and animal models. In: Holly FJ, editor. The preocular tear film in health, disease and contact lens wear. Lubbock, Texas: Dry Eye Institute, 1994: 471-88.

128. Ubels JL, McCartney MD, Lantz WK, Beaird J, Dayalan A, Edelhauser HF. Effects of preservativefree artificial tear solutions on corneal epithelial structure and function. Arch Ophthalmol 1995;113: $371-8$.

129. Gilbard JP, Rossi SR, Heyda KG. Ophthalmic solutions, the ocular surface, and a unique therapeutic artificial tear formulation. Am J Ophthalmol 1989; 107:348-55.

130. Bron AJ, Tiffany JM. Pseudoplastic materials as tear substitutes. In: van Bijsterveld PO, Lemp MA, Spinelli D, editors. An exercise in design. A selection of papers presented at the 6th international symposium on the lacrimal system, Singapore. Amsterdam: Kugler \& Ghedini, 1990:27-33.

131. Solomons A, Merin S. The effect of a new tear substitute containing glycerol and hyaluronate on keratoconjunctivitis sicca. Submitted.

132. Mircheff AK, Warren DW, Wood RL. Hormonal support of lacrimal function, primary lacrimal deficiency, autoimmunity and peripheral tolerance in the lacrimal gland. Ocular Immunol Inflamm 1996;4:1-28.
133. Sullivan DA, Wickham LA, Krenzer KL, Rocha EM, Toda I. Aqueous tear deficiency in Sjögren's syndrome: possible causes and potential treatment. In: Pleyer U, Hartmann C, Sterry W, editors. Oculodermal diseases: immunology of bullous oculo-mucocutaneous disorders. Buren, The Netherlands: Aeolus Press (in press).

134. Gilbard JP, Rossi SR, Heyda KG, Dartt DA. Stimulation of tear secretion and treatment of dryeye disease with 3-isobutyl-1-methylxanthine. Arch Ophthalmol 1991;109:672-6.

135. Ki ang E, Garcia CA, Castellanos MG. Evaluation of oral pilocarpine as a tear secretion stimulator in the treatment of dry eye \{abstract 4600]. Invest Ophthalmol Vis Sci (ARVO Suppl) 1995;36:S994.

136. Kaswan R. Characteristics of a canine model of KCS: effective treatment with topical cyclosporine. Adv Exp Med Biol 1994;350:583-94.

137. Kaswan RL, Salisbury MA. A new perspective on canine keratoconjunctivitis sicca: treatment with ophthalmic cyclosporine. Vet Clin North Am Small Anim Pract 1990;20:583-613.

138. Kaswan RL, Salisbury MA, Ward DA. Spontaneous canine keratoconjunctivitis sicca: a useful model for human keratoconjunctivitis sicca treatment with cyclosporine eyedrops. Arch Ophthalmol 1989;107: 1210-6.

139. Fullard RJ, Kaswan RM, Bounous DI, Hirsh SG. Tear protein profiles vs clinical characteristics of untreated and cyclosporine-treated canine KCS. J Am Optom Assoc 1995;66:397-404.

140. Stern ME, Gelber TA, Gao J, Ghosn CR. The effects of topical cyclosporine A (CsA) on dry eye dogs (KCS) [abstract 4715]. Invest Ophthalmol Vis Sci (ARVO Suppl)1996;37:S928.

141. Foulks GN, Plugfelder SC, Lemp MA, Stern KL, Burk CT, Reis BL. A randomised double-masked clinical trial to assess efficacy and safety of a $1 \%$ CsAcontaining ophthalmic ointment vs placebo in patients with keratoconjunctivitis sicca (KCS) associated with Sjögren's syndrome [abstract 2992]. Invest Ophthalmol Vis Sci (ARVO Suppl) 1996;37:S646.

142. Helms HA, Rapoza P, Stern KL, Burk CT, Rosenthal A, Reis BL. A randomised double-masked clinical trial to assess the safety and comparative efficacy of three concentrations of a cyclosporine-containing ophthalmic ointment vs placebo in patients with keratoconjunctivitis sicca (KCS) [abstract 2993]. Invest Ophthalmol Vis Sci (ARVO Suppl) 1996;37:S646.

143. Rudnick DE, Edelhauser HF, Hendrix LC, Rodeheaver DP, Hackett RB. Electrophysiological evaluation of ophthalmic preservatives on corneal epithelial junctions, structure, and function [abstract 4604]. Invest Ophthalmol Vis Sci (ARVO Suppl) 1995; 36:S995.

144. McCarey BE, Reaves TA. Artificial tear preparations affect in vivo corneal epithelial permeability [abstract 4603]. Invest Ophthalmol Vis Sci (ARVO Suppl) 1995;36:S995.

145. Chibret H, Goldschmidt P, Pouliquen P, Rondepierre A, Defemme A, Luyckx J, Coquel T. Preservatives on the ocular surface: new technology (ABAK) able to capture irreversibly benzalkonium chloride (BAK) from eye-drops [abstracts 2651]. Invest Ophthalmol Vis Sci (ARVO Suppl) 1996;37:S576. 
146. Lamberts DW. Punctal occlusion. In: Smolin G, Friedlaender $\mathrm{MH}$, editors. International ophthalmology clinics: dry eye. 1st ed. Boston, Mass: Little, Brown, 1994:145-50.

147. Murube-del-Castillo J, Hernandez-King J. Treatment of dry eye by moving the lacrimal punctum to dry dock. Ophthalmic Surg 1993;24:53-8.

148. Bertera JH. A prototype piezo jet pump irrigator for dry eye [abstract 4599]. Invest Ophthalmol Vis Sci (ARVO Suppl) 1995;36:S994.
149. Dohlman CH, Doane MG, Reshmi CS. Mobile infusion pumps for continuous delivery of fluid and therapeutic agents to the eye. Ann Ophthalmol 1971;3:126-8.

150. Bron AJ, Tiffany JM, Embleton J, Martini LM, Taylor S. Topical delivery of microvolumes to the eye, using a forced flow system. In: Second international dry eye conference, Bermuda, 1996 (in press).

151. Lemp MA. General measures in management of the dry eye. Int Ophthalmol Clin 1987;27:36-43. 